\title{
2019 Practice guidelines for thyroid core needle biopsy: a report of the Clinical Practice Guidelines Development Committee of the Korean Thyroid Association
}

\author{
Chan Kwon Jung ${ }^{1,2}$, Jung Hwan Baek ${ }^{3}$, Dong Gyu Na ${ }^{4}$, Young Lyun $\mathrm{Oh}^{5}$, Ka Hee $\mathrm{Y}^{6}$, Ho-Cheol Kang ${ }^{7}$, \\ Clinical Practice Guidelines Development Committee of the Korean Thyroid Association \\ ${ }^{1}$ Department of Hospital Pathology, College of Medicine, The Catholic University of Korea, Seoul; \\ ${ }^{2}$ Cancer Research Institute, College of Medicine, The Catholic University of Korea, Seoul; \\ ${ }^{3}$ Department of Radiology and Research Institute of Radiology, Asan Medical Center, University of Ulsan College of Medicine, Seoul; \\ ${ }^{4}$ Department of Radiology, Gangneung Asan Hospital, University of Ulsan College of Medicine, Gangneung; \\ ${ }^{5}$ Department of Pathology and Translational Genomics, Samsung Medical Center, Sungkyunkwan University School of Medicine, Seoul; \\ ${ }^{6}$ Department of Internal Medicine, Seoul Metropolitan Government Seoul National University Boramae Medical Center, Seoul; \\ ${ }^{7}$ Department of Internal Medicine, Chonnam National University Hwasun Hospital, Chonnam National University Medical School, Hwasun, Korea
}

\begin{abstract}
Ultrasound-guided core needle biopsy (CNB) has been increasingly used for the pre-operative diagnosis of thyroid nodules. Since the Korean Society of the Thyroid Radiology published the 'Consensus Statement and Recommendations for Thyroid CNB' in 2017 and the Korean Endocrine Pathology Thyroid CNB Study Group published 'Pathology Reporting of Thyroid Core Needle Biopsy' in 2015, advances have occurred rapidly not only in the management guidelines for thyroid nodules but also in the diagnostic terminology and classification schemes. The Clinical Practice Guidelines Development Committee of the Korean Thyroid Association (KTA) reviewed publications on thyroid CNB from 1995 to September 2019 and updated the recommendations and statements for the diagnosis and management of thyroid nodules using CNB. Recommendations for the resolution of clinical controversies regarding the use of CNB were based on expert opinion. These practical guidelines include recommendations and statements regarding indications for CNB, patient preparation, CNB technique, biopsy-related complications, biopsy specimen preparation and processing, and pathology interpretation and reporting of thyroid CNB.
\end{abstract}

Key Words: Thyroid gland; Thyroid nodule; Thyroid neoplasms; Biopsy, Fine-Needle; Core needle biopsy

Received: November 21, 2019 Accepted: December 4, 2019

Corresponding Author: Chan Kwon Jung, MD, PhD, Department of Pathology, Seoul St. Mary's Hospital, College of Medicine, The Catholic University of Korea, 222 Banpo-daero, Seocho-gu, Seoul 06591, Korea

Tel: +82-2-2258-1622, Fax: +82-2-2258-1627, E-mail: ckjung@catholic.ac.kr

Corresponding Author: Jung Hwan Baek, MD, PhD, Department of Radiology and Research Institute of Radiology, Asan Medical Center, University of Ulsan College of Medicine 88 Olympic-ro 43-gil, Songpa-gu, Seoul 05505, Korea

Tel: +82-2-3010-4348, Fax: +82-2-476-0090, E-mail: radbaek@naver.com

Ultrasound (US)-guided fine-needle aspiration (FNA) is a cost-effective and safe tool for the assessment of thyroid nodules and has been used as a standard diagnostic modality for the management of thyroid nodules [1,2]. In the 1980s, FNA became the standard diagnostic tool for thyroid nodules, replacing large-needle biopsy because of its high diagnostic accuracy and low complication rate [3]. The main clinical role of FNA is to rule out malignant tumors requiring surgery. The use of FNA has reduced the number of unnecessary surgeries in patients with thyroid nodules. Although FNA is associated with high diagnos- tic accuracy and safety, it has several limitations due to a substantial rate (approximately 22.4\%) of inconclusive results including non-diagnostic or atypia of undetermined significance (AUS)/follicular lesion of undetermined significance (FLUS) [4]. The non-diagnostic rate in initial FNA is about $10 \%$ and an even higher rate of up to $50 \%$ in repeat FNA [5,6]. The rate of AUS/FLUS is about $10 \%-20 \%$ with higher rates of inconclusive results in repeat FNA [7-10]. FNA also shows a relatively low diagnostic accuracy for follicular lesions $[11,12]$. These limitations associated with FNA lead to repeated FNA or unnecessary 
surgeries. Therefore, additional diagnostic tools for thyroid nodules are desirable to overcome the limitations of FNA for thyroid nodule assessment.

Advances in core needle biopsy (CNB) have led to the use of spring-activated single- or double-action needles in thyroid nodule diagnosis. In addition, widespread use of high-resolution US enables accurate diagnosis and minimization of complications associated with CNB in head and neck lesions [13]. CNB is safe, well-tolerated, and associated with a low incidence of complications when performed by an expert $[1,14]$. Several largescale studies $[15,16]$ and a systematic review and meta-analysis [17] validated the low rates of major and minor complications and absence of procedure-related deaths.

$\mathrm{CNB}$ has the potential to overcome the limitations of FNA by obtaining a large tissue sample, which reduces non-diagnostic results due to paucity of follicular cells and provides further information related to histological architecture underlying the capsule. Previous studies [18-21] reported that CNB yielded a lower rate of inconclusive results, including non-diagnostic or AUS/ FLUS results compared with repeated FNA in the assessment of nodules with prior inconclusive results. Recently, several studies also reported the potential role of $\mathrm{CNB}$ as a first-line diagnostic tool for the management of thyroid nodules [22-25].

Together with thyroid FNA and CNB, a multidisciplinary approach for patients with a thyroid nodule is essential to improve the quality of life and achieve a better outcome. Standardized guidelines are needed to ensure the optimal management of patients with thyroid nodules. The terminology for reporting thyroid FNA cytology worldwide is based on the Bethesda System for Reporting Thyroid Cytopathology (TBSRTC), which was introduced in 2007. The second edition of TBSRTC was released in 2017 [26]. The Korean Society of Thyroid Radiology (KSThR) published 'Core needle biopsy of thyroid nodules: consensus statement and recommendations' in 2013 [27]. The Korean Endocrine Pathology Thyroid CNB Study Group published an initial proposal of 'Pathology Reporting of Thyroid Core Needle Biopsy' in 2015 [28]. In 2017, the KSThR published 'Core Needle Biopsy of the Thyroid: 2016 Consensus Statement and Recommendations from the Korean Society of Thyroid Radiology' [14]. The fourth edition of the World Health Organization (WHO) classification of endocrine tumors was released in 2017 [29]. The 2017 revisions of TBSRTC and the WHO classification in thyroid cytology and histopathology encompass molecular diagnostics and new diagnostic entities of borderline thyroid tumors such as noninvasive follicular thyroid neoplasm with papillary-like nuclear features (NIFTP).
Along with recent advances in the diagnostic classification and management guidelines of thyroid nodules, the Practice Guideline Committee of the Korean Thyroid Association (KTA) organized a taskforce for the development of practical guidelines of $\mathrm{CNB}$ for the diagnosis and management of thyroid nodules. This guideline includes the indications, patient preparation, biopsy technique, complications, specimen preparation, and pathology reporting.

\section{METHODS}

A search of the PubMed, MEDLINE, and EMBASE databases was performed to retrieve publications on thyroid CNB from 1995 to September 2019 using the following keywords: (thyroid nodule OR thyroid cancer OR thyroid carcinoma OR thyroid malignancy OR thyroid neoplasm OR thyroid diagnosis) and (core needle biopsy OR core-needle biopsy OR core biopsy OR gun biopsy OR CNB). Since clinical controversies related to issues exist in many of the areas, the recommendations regarding some of the issues are based on expert opinion. This limitation needs to be overcome in the near future when new elements of evidence are accumulated. Because there is little high-level evidence, recommendations regarding some of the issues are based on expert opinion. This limitation needs to be addressed in the future based on further studies. The goal of this guideline is to provide the best scientific evidence available and a consensus expert opinion regarding the clinical use of $\mathrm{CNB}$ in thyroid nodules.

\section{INDICATIONS FOR CORE NEEDLE BIOPSY}

The indications for $\mathrm{CNB}$ have yet to be clearly defined. Most thyroid guidelines recommend FNA as a first-line biopsy for thyroid nodule assessment; therefore, CNB is regarded as a complementary tool [14,30-32]. Recently, KSThR published the CNB Guideline in 2017 [14]. KSThR suggested several indications and the possible use of CNB for thyroid nodules with non-diagnostic or indeterminate FNA results. The National Cancer Institute (NCI) suggested that CNB under US guidance utilizing modern needles may be advantageous in cases rendered "unsatisfactory" by FNA [32]. In addition, the American Association of Clinical Endocrinologists (AACE)/American College of Endocrinology (ACE)/Associazione Medici Endocrinologi (AME), British Thyroid Association (BTA), and KSThR suggested the use of CNB for malignant thyroid tumors such as lymphoma, anaplastic cancer, medullary cancer, and metastasis $[14,30,33]$. However, the American Thyroid Association (ATA) 
did not recommend the use of CNB for thyroid tumors [31].

A meta-analysis showed that the non-diagnostic and inconclusive rates of $\mathrm{CNB}$ were $5.5 \%$ (95\% confidence interval [CI], $2.2 \%$ to $8.7 \%$ ) and $8.0 \%$ (95\% CI, $4.4 \%$ to $11.5 \%$ ), respectively, whereas the non-diagnostic and inconclusive rates of FNA were $22.6 \%$ (95\% CI, $12.2 \%$ to $33.0 \%$ ) and $40.2 \%$ (95\% CI, $25.1 \%$ to $55.3 \%$ ), respectively [34-36]. In another meta-analysis focusing on initially non-diagnostic FNA results, the nondiagnostic rate $(6.4 \%$; $95 \% \mathrm{CI}, 3.3 \%$ to $16.1 \%)$ of follow-up CNB was significantly lower than that of repeated FNA (36.5\%; 95\% CI, 29.9\% to 43.1\%) [35,36]. In large cohort CNB studies, the false-negative rate of $\mathrm{CNB}$ ranged from $1 \%$ to $3 \%$ [35,37-39]. Recently, several studies suggested the initial use of $\mathrm{CNB}$, but it is still disputed $[23,37,38,40]$.

Based on current evidence, CNB has been suggested as the next diagnostic method for previously non-diagnostic FNA results [18,19,41,42], previous AUS/FLUS [18,43-45], and clinically suspected rare thyroid malignancies [13,46-49].

\section{PREPARING PATIENTS FOR CORE NEEDLE BIOPSY}

First, informed consent should be obtained and should include the information needed for the CNB procedure and possible complications [14]. The side effects associated with the use of drugs (i.e. bleeding tendency with drugs such as warfarin, heparin, aspirin, or clopidogrel bisulfate) should be evaluated, however, a screening blood test for coagulation is usually unnecessary. The KSThR guideline recommends withdrawal of aspirin and clopidogrel bisulfate for 7-10 days, warfarin for 3-5 days, and heparin for 4-6 hours before CNB [14]. Initiation of aspirin and clopidogrel bisulfate after $\mathrm{CNB}$ is recommended from the next day followed by warfarin at night, and heparin 2 hours later $[14,50]$. Considering the clinical significance of anticoagulant therapy, the withdrawal of anticoagulant should be carefully discussed with the prescribing physician. Warfarin can be transiently changed to shorter-acting heparin $[14,50]$. Fasting is usually not recommended for CNB in most patients [14].

\section{PLANNING THE CORE NEEDLE BIOPSY PROCEDURE}

Before the procedure, the nodule characteristics, size, location, and vascularity should be evaluated on gray-scale US and color Doppler US. Careful monitoring of vascularity with color Doppler US can minimize bleeding during CNB [14]. The CNB approach route is decided based on the information obtained from the pre-procedural US. Among the four approach routes available including transisthmic, lateral, longitudinal, and oblique [14], the trans-isthmic approach is considered the most suitable. The nodule size and location are important factors in deciding the size of specimen notch $[14,18,39]$. To improve the safety and diagnostic accuracy, CNB should be performed by experienced operators under US guidance [14].

\section{PREPARATION OF CORE BIOPSY EQUIPMENT}

Before 2000, large-bore needles (14-gauge) had been used for large-needle biopsy $[14,51]$. Recent CNB devices are characterized by small bore (usually 18-21 gauge) and spring activation [14,18,51-53].

The KSThR recommends appropriate CNB needle conditions for thyroid nodules [14]. First, a short needle length (less than $10 \mathrm{~cm}$ ) is recommended since thyroid gland is a superficial organ. Second, needle bore determines the thickness of the specimen. The thinner the needle, the less damage to normal tissue but the lower is the amount of tissue obtained [14]. Some studies report the use of 16-22 gauge needles [18,41,53-55]. Although the use of 18-21 gauge needles is universal for thyroid nodules, 18 -gauge needles have been mainly used in Korea $[14,18,43,56-$ 58]. Finally, the stylet length or the penetration length can be selected according to the nodule size. Thickness of core needle is another issue. Ahn et al. [59] reported that CNB with an 18-gauge needle is more effective for the diagnosis of thyroid nodules than $\mathrm{CNB}$ with a 20-gauge needle. However, there is insufficient evidence supporting the relationship between needle thickness and complication rate or diagnostic accuracy.

CNB needles are composed of two needles, the stylet and the cutting cannula $[14,18,52]$. The stylet (inner needle) carries an approximately 2-mm-long tip with a sharp slope to penetrate tissue and a specimen notch to hold the sampled tissue. The cutting cannula (outer needle) is the outer component for cutting the tissue [14].

Core biopsy devices are divided into automated and semi-automated types according to the mechanism of action [14]. The automated needle is known as the double-action device because both inner and outer needles are activated by spring action. This type of needle fires the inner needle by the action of a spring that can more easily penetrate hard fibrotic or calcified tissue. However, it may be more prone to tissue or vessel damage. The semi-automated needle is known as a single-action needle because the spring activates only once: the inner needle is manually ad- 
vanced, followed by the spring-activated outer cutting needle. The semi-automated needle is relatively safe, since operators manually push the inner needle into the tissue [14]. The amount of tissue obtained depends on the needle thickness and the length of the specimen notch $[35,60]$.

\section{SAMPLING TECHNIQUES FOR CORE NEEDLE BIOPSY}

Two options for needle guidance are available during USguided CNB: a free-hand and a needle device under US guidance [29]. The KSThR Guideline recommends the free-hand technique (especially for experts) because it allows greater freedom for the operators in selecting the puncture point and adjusting the route during the procedure [14].

Patients lie down in a supine position under local anesthesia along the approach route. After vessel mapping using color Doppler US, a snapping wrist movement is favored for rapid and effective needle passage through the skin and thyroid capsule [14]. The entire length of the needle must be monitored during the procedure. Complete vessel mapping along the approach route (from the skin to the nodule) is crucial to avoid vessel injury and ensure safety of the procedure [14].

The number of core specimens is debatable. Hahn et al. [61] suggested at least two core specimens including a nodular tissue and a capsule for nodules with previous inconclusive cytology. The length of the core specimen is also important in that a large length decreases the biopsy number $[38,62]$. Suh et al. [38] performed less than two core biopsies; however, inconclusive results were not high in their factor analysis. Multiple biopsies can trigger further complications, which should be considered during CNB procedures [38].

Most importantly, the entire length of the needle and needle tip should be ensured during the CNB procedure $[14,63]$. The needle tip must be within thyroid capsule without large vessels along the imagined firing route. Further, the stylet can be fired followed by the cutting cannula (Fig. 1). When a successful method is used, the location of the specimen notch can be adjusted after stylet firing to select the most appropriate sampling site. Many studies suggest that the nodule tissue, nodule-parenchyma border (and/or visible capsule), and normal thyroid parenchyma should be obtained [14,54,60,64,65]. Nodules found in a dangerous location should be carefully evaluated. A single-action needle is safer because it enables fine adjustment of the specimen notch [14].

Occasionally, thyroid nodules exhibit severe fibrosis and/or hard calcifications. To successfully obtain samples from such hard nodules, using a double-action core needle is useful [14,6669]. A guiding (coaxial) needle is useful for multiple CNB. In this technique, the biopsy needle is inserted through the lumen of the guiding needle, which is located from the skin close to the nodule surface. After CNB, the tissue sample can be visually assessed to determine if additional CNB is required [14,18,39, 42,66]. After visual assessment, the harvested tissue should be immediately fixed in formalin. One to two biopsies are adequate for histological diagnosis. Manual compression should be performed immediately after the biopsy for 20 to 30 minutes [14].

\section{BIOPSY-RELATED COMPLICATIONS}

The KSThR or NCI guidelines suggest that CNB is safe, welltolerated, and associated with a low incidence of complications when performed by experienced operators [14,18,32,41]. The reported complication rate is up to $4.1 \%$, with the major complication rate up to $1.9 \%[16,43,53,55,58,70]$. Various CNB complications were reported [14], including hematoma [18,39,41, $53,70]$, voice change [43,55], infection [70,71], hemoptysis [41], edema [18,39,42], vasovagal reaction [70], and dysphagia [70]. A large single-center study (6,687 thyroid nodules of 6,169 patients) reported few major and minor complications $(4 / 6,169$ [0.06\%] and 49/6,169 [0.79\%], respectively) and no procedurerelated death or sequelae [15]. A systematic review showed that the major complications including permanent voice changes, hematomas requiring hospital admission and a pseudoaneurysm, and minor complications were reported in six $(0.04 \%)$ and 175 $(1.18 \%)$ out of a total of 14,818 patients in 39 thyroid CNB studies from January 1994 to December 2016, respectively [17].

To avoid complications, CNB should be performed by an expert [14] with knowledge of anatomy, anatomic variations, and potential complications [72].

CNB is generally associated with pain and discomfort. USguidance and the use of 18-21 gauge thin needles (commonly 18-gauge) can reduce the level of pain and the rate of complications [14]. Several studies compared FNA and CNB in terms of pain and tolerability and concluded that they were similar in both procedures [73-75]. A recent study reported that the overall satisfaction scores at 2 weeks after the procedure did not differ significantly between patients who underwent FNA and CNB [75].

Hematoma induced by vascular injury is the most common complication in thyroid $\mathrm{CNB}$ with a reported incidence of up to $3.9 \%[14,15,76]$, which is similar to that of FNA $(1 \%-6.4 \%)$ [77]. Parenchymal edema induced by small vessel injury is fre- 
quently associated with hematoma and pain $[18,39,42,66]$. These vascular injuries are mostly managed with simple compression without the need for medication in most cases $[14,18,39]$. A few cases of hematoma have been reported after $\mathrm{CNB}$ as a major complication [53,78]. To prevent these complications, manual compression should be performed immediately after the biopsy for 20 to 30 minutes to prevent the risk of delayed hematoma $[18,42]$.
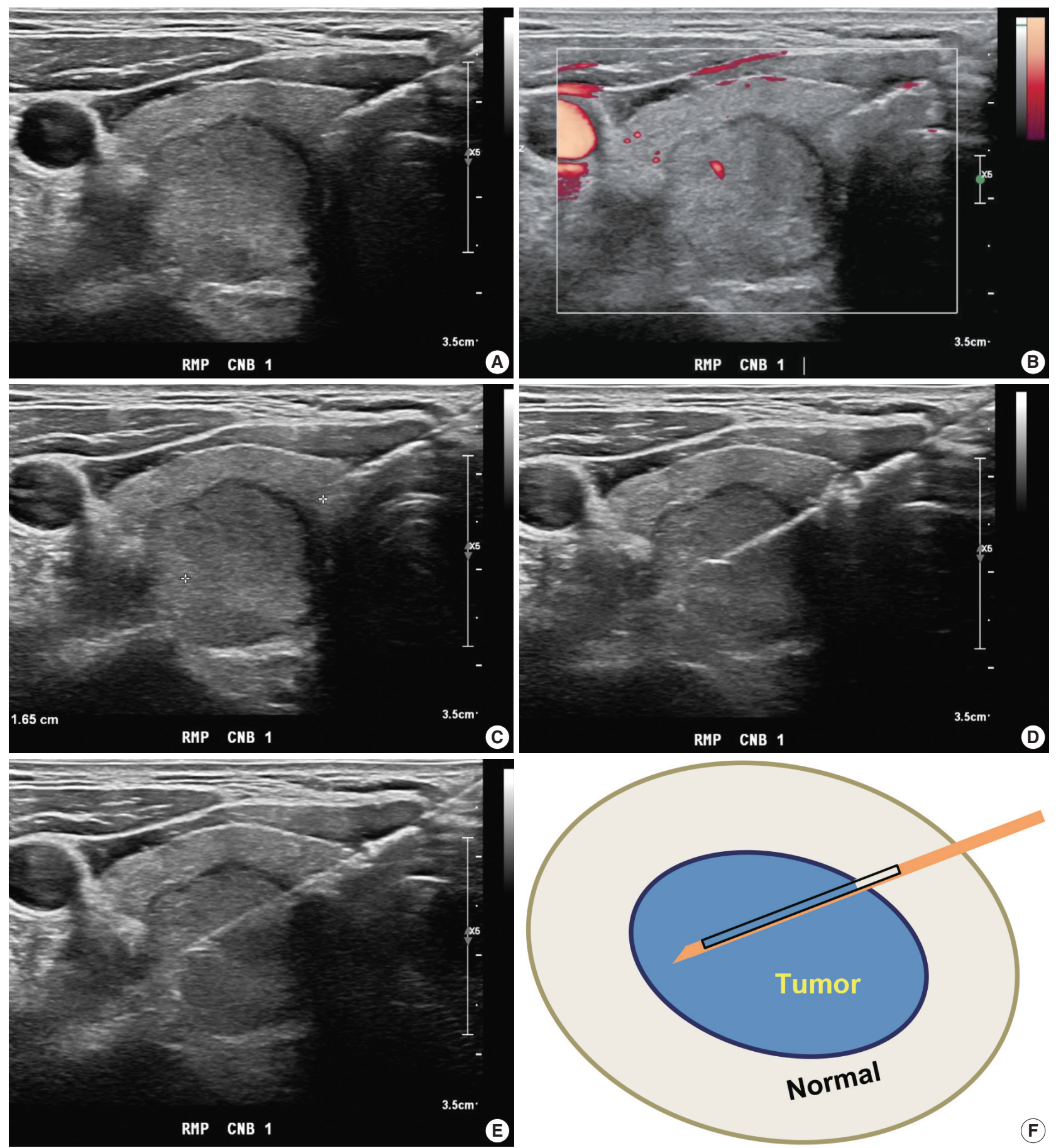

Fig. 1. Core needle biopsy of right thyroid nodule. (A) Core needle approach is made through isthmus. (B) Vessels are evaluated with Doppler ultrasound advanced along the direction of the needle. (C) Measurement of distance of fire. (D, E) Firing the stylet first followed by cutting cannula. (F) Schematic illustration of core needle biopsy showing the biopsy site. A cylindrical core of tissue includes tumor and adjacent non-tumor tissue. 
Voice change, caused by direct injury or indirect injury due to bleeding or edema to the recurrent laryngeal nerve, is a rare but serious complication after thyroid CNB [37]. A systematic review showed that the overall incidence of permanent and transient voice change after thyroid CNB was $0.0013 \%(2 / 14,818)$ and $0.034 \%(5 / 14,818)$, respectively [17]. The highest incidence $(1.9 \%, 1 / 54)$ of voice change was observed in a small study [43]. Recurrent laryngeal nerve palsy associated with hemorrhage/ edema is usually transient $[14,79]$. A trans-isthmic approach under US monitoring is important to prevent direct injury to the recurrent laryngeal nerve [14,72]. A lateral-to-medial approach is dangerous to trachea, esophagus or recurrent laryngeal nerve [16].

Abscess formation is a very rare complication after CNB due to the rich vascular supply and lymphatic drainage, and high iodine content in the thyroid [14,71]. Therefore, the application of prophylactic antibiotics is not recommended before or after CNB.

In the case of a nodule located at the posteromedial margin of the thyroid, CNB is indicated after excluding a pharyngoesophageal or esophageal diverticulum $[14,72,80]$. Direct injury to the trachea induces cough or hemoptysis [41]. Tinnitus, a rare complication, has been attributed to injury of the perithyroidal vertebral artery and vein followed by an arteriovenous fistula [81]. Tumor seeding after $\mathrm{CNB}$ has not been reported but is a possible rare complication [82]. For safe and effective CNB procedure, operators should be familiar with the broad spectrum of complications and preventive methods [14].

\section{PATHOLOGY REQUEST FORM}

The request form for $\mathrm{CNB}$ should include the following information: identification of the patient sample: patient's name, date of birth, unit number or medical record number; name of the requesting clinician and the clinician who performed the procedure; side and site of the lesion; number of biopsy cores; US imaging findings; and relevant clinical history.

\section{PREPARATION AND PROCESSING OF CORE NEEDLE BIOPSY SPECIMENS}

Proper tissue processing and histological staining procedures are essential for subsequent pathologic diagnosis. Biopsy specimens are fragile and should be handled with caution. As soon as the biopsy tissues are removed from the thyroid gland, biopsy cores should be wrapped in saline- or fixative-moistened gauze or filter paper to prevent specimen loss and tissue folding, and rap- idly fixed with $10 \%$ neutral buffered formalin (NBF) (which is equivalent to $4 \%$ formaldehyde) to inhibit autolysis and putrefaction. Squeezing of biopsy specimen must be avoided to prevent cell rupture and loss of cell identity when examined microscopically. If a fixative cannot be added in a timely manner, the specimen should be wrapped in a moist saline gauze and refrigerated until the specimen is treated with an appropriate fixative. The ratio of formalin solution to tissue should be at least 10:1 with $10 \mathrm{~mL}$ of the fixative for every gram of tissue $[83,84]$. In clinical practice, the adequate volume of $10 \% \mathrm{NBF}$ should be 15-20 times the specimen volume. The fixation time depends on sample size. Adequate fixation time with $10 \%$ NBF usually requires a minimum of 5 hours of exposure for small biopsy specimen [84]. However, practices may vary between laboratories. Incomplete or poor tissue fixation can lead to poor and unsatisfactory results. All specimens must be placed in a leak-proof container.

Sections obtained from formalin-fixed paraffin-embedded tissue blocks can be used for routine hematoxylin and eosin staining or ancillary tests such as special stain, immunohistochemistry, and molecular tests.

\section{PATHOLOGY REPORTING FOR THYROID CORE NEEDLE BIOPSY}

The first edition of 'Pathology Reporting of Thyroid Core Needle Biopsy' published in 2015 by the Korean Endocrine Pathology CNB Study Group has been widely used by Korean pathologists [28]. A recent study performed in China showed that the pathology reporting system of thyroid CNB is objective, operable and valuable for the pathologic diagnosis of thyroid nodules clinically [85].

The thyroid CNB pathology must be correlated with clinical and US imaging findings. The biopsy results should be reviewed in conjunction with matching surgical pathology after surgery.

A categorical reporting system for $\mathrm{CNB}$ ensures effective communication between pathologists and clinicians, with less likelihood of misinterpretation of pathology results. The six original general categories have been retained in the 2019 revision.

To communicate with clarity, the pathology report of thyroid CNB begins with a general diagnostic category. The six general diagnostic categories are shown in Table 1. Subcategorization is often informative especially in diagnostic categories III and IV. A brief microscopic description of the biopsy specimen can be informative, but should not be used alone to report the diagnosis. The standardized terms for the diagnostic categories should be 
Table 1. Diagnostic categories of thyroid core needle biopsy



used. The numerical code alone should not be used without the term of diagnostic category. The risk of malignancy and recommendations associated with each general category are not required but can be provided based on their own CNB-histology correlation or published studies.

\section{Non-diagnostic or unsatisfactory}

This category is used when the volume of biopsy specimen and the number of follicular cells is inadequate or unsatisfactory to obtain appropriate diagnosis or when the specimen is not representative of US imaging findings of the lesion. The adequacy of the specimen may depend on the inherent nature of the thyroid lesion as well as the experience and technique of the technician conducting the biopsy. This diagnosis is subjective as there is no consensus on the minimum number or amount of follicular components required for satisfactory biopsy specimen. Therefore, the report should explain why the sample is non-diagnostic or unsatisfactory. For example, the sample may be non-tumor tissue adjacent to thyroid (Fig. 2A), extrathyroid tissue alone (e.g., skeletal muscle and mature adipose tissues) as shown in Fig.
2B, an acellular specimen (Fig. 2C, D), or a blood clot. It may show other non-diagnostic or unsatisfactory findings. However, any $\mathrm{CNB}$ specimen containing atypical cells should not be considered non-diagnostic or unsatisfactory.

Non-tumor adjacent thyroid tissue or extrathyroid tissue only implies that the thyroid lesion has not been sampled. For some benign follicular lesions with normofollicular structures (Fig. 2A), it may be difficult to assess specimen adequacy because follicular cells of the thyroid nodule show similar histological features with the adjacent thyroid tissue. It is important to determine the transition between the follicular lesion and the surrounding normal parenchyma and compare the pathologic findings with its US imaging results.

\section{Benign}

This category includes all benign thyroidal and nonthyroidal diseases. A CNB specimen can be classified, based on the specific lesion diagnosis, under the benign category. For example, the sample may be a benign follicular nodule, Hashimoto's thyroiditis, subacute granulomatous thyroiditis, a nonthyroidal lesion 

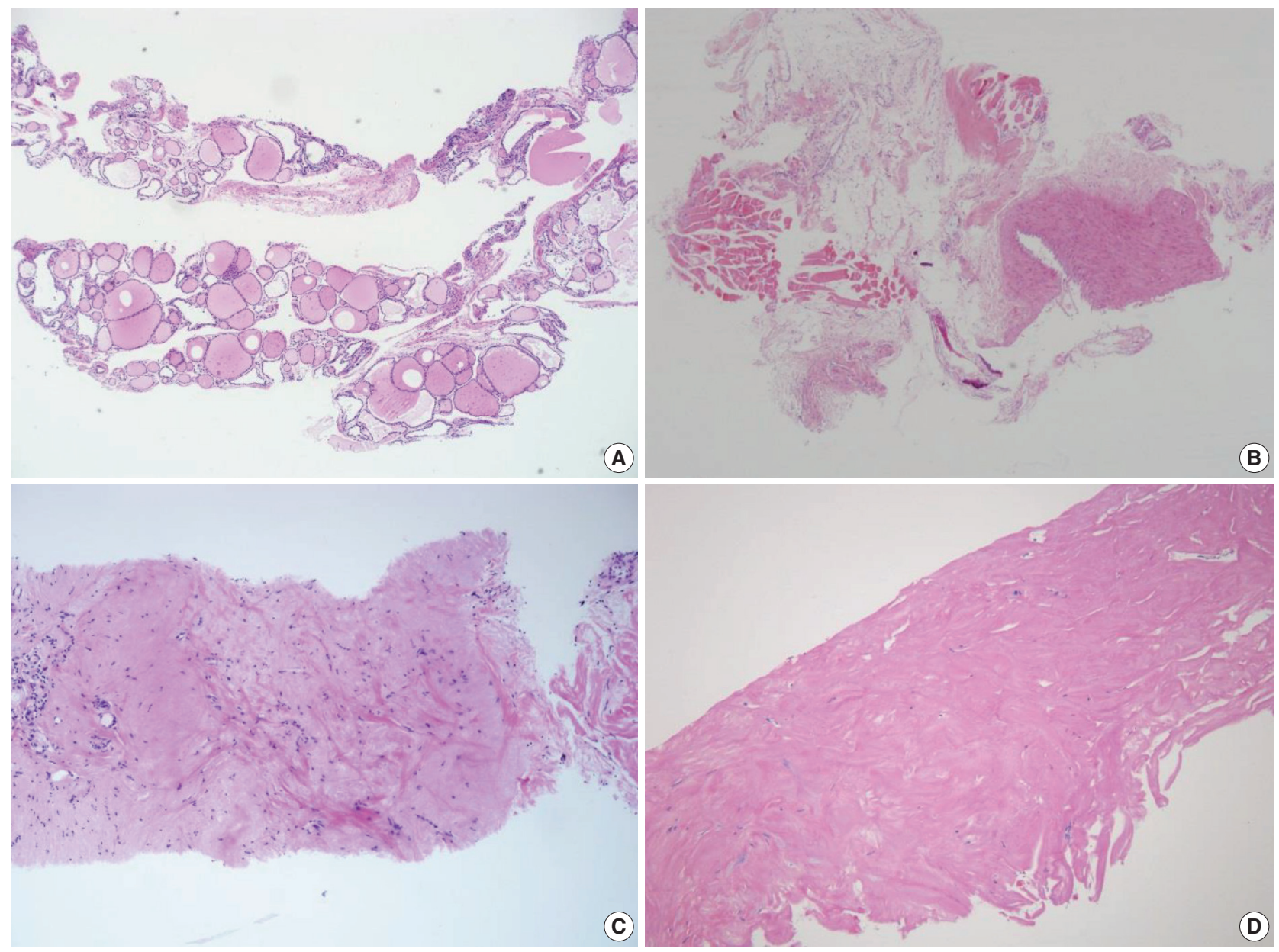

Fig. 2. Examples of non-diagnostic specimens (category I) in thyroid core needle biopsy. The examples include non-tumor adjacent thyroid tissue only (A), extrathyroidal soft tissue only (B), and acellular sclerotic nodules (C, D).

(e.g., a parathyroid lesion, benign neurogenic tumors, benign lymph node), or other benign lesions.

A benign follicular nodule encompasses nodular hyperplasia (adenomatoid nodule), colloid nodule, a nodule associated with Graves' disease, nodular Hashimoto's thyroiditis, and a subset of follicular adenoma. CNB specimens of these lesions show a benign-appearing normofollicular or macrofollicular structure and do not contain a well-defined fibrous capsule (Fig. 3A, B).

Most degenerating nodules are benign but they often show suspicious US findings and non-diagnostic or indeterminate cytologic results [69]. CNB of degenerating nodule according to the progression stage shows hemorrhagic materials in early phase, stromal fibrosis, and hyalinization infiltrated with chronic inflammatory cells after regression of hemorrhage in the middle phase, and paucicellular densely hyalinized stroma in late phase [69]. In a $\mathrm{CNB}$ specimen of degenerating nodule, the lesion can be diagnosed as a benign degenerating nodule if there are no atypical cells in the fibrous hyalinized and/or hemorrhagic background with scarce follicular cells (Fig. 3C, D) [69]. The atypia status can be determined by comparing the histologic features of follicular cells in both the central and peripheral regions included in the CNB specimen. Benign Hürthle cell lesions often occur in patients with Hashimoto's thyroiditis and may resemble their neoplastic counterparts. The presence of lymphoid aggregates within the Hürthle cell lesion favors a diagnosis of benign (category II) over indeterminate Hürthle cell lesion (category IIId) or Hürthle cell neoplasm (category IVc) (Fig. 3E, F).

\section{Indeterminate lesion}

Cytological atypia and histological growth patterns in this category are of uncertain significance and insufficient to be classified under other diagnostic categories. The diagnostic category III "indeterminate lesion" corresponds to "AUS" or "FLUS" in TBSRTC. Most Korean pathologists prefer the term "indeter- 

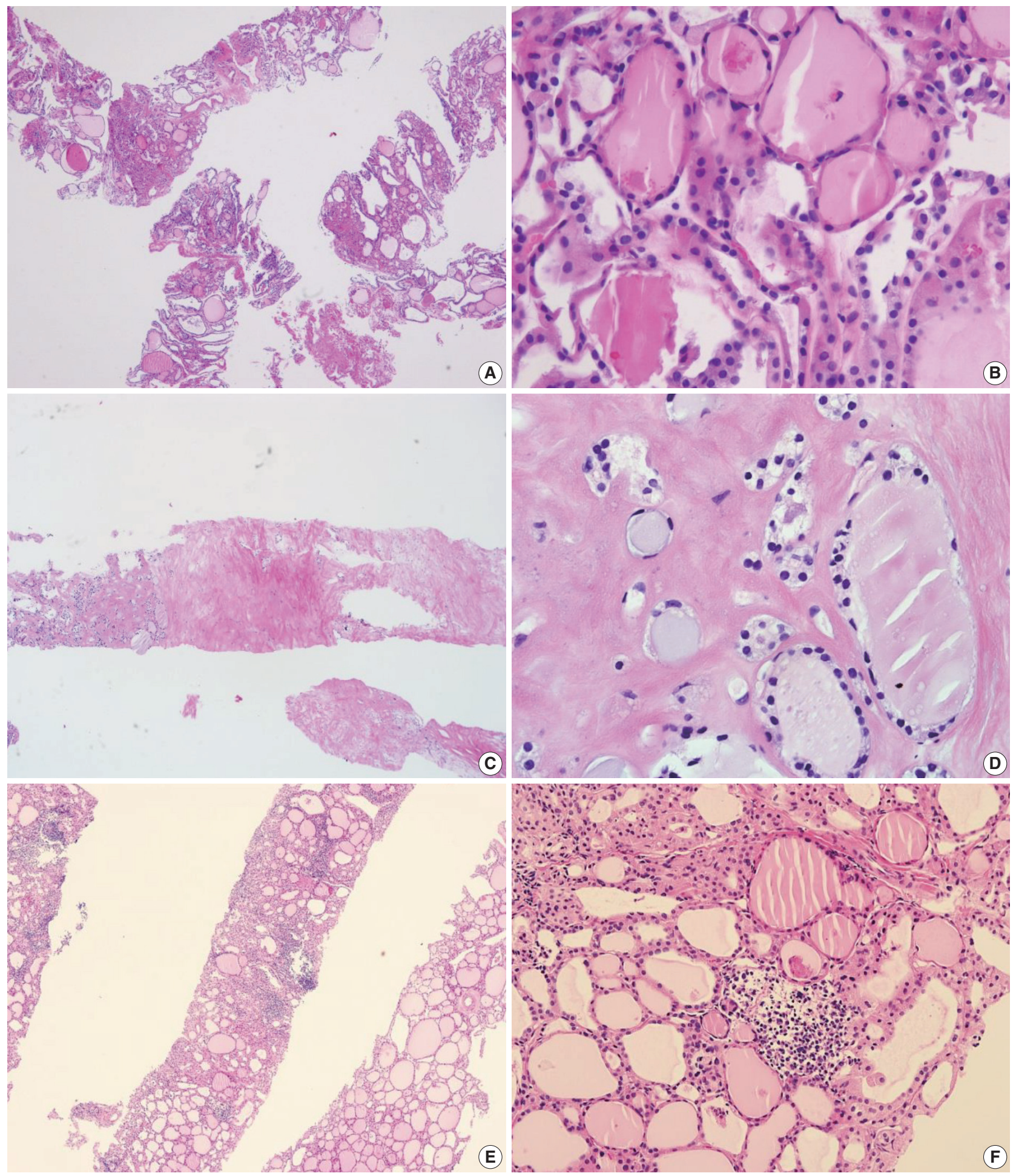

Fig. 3. Examples of benign nodules (category II) in thyroid core needle biopsy. (A) The biopsy specimen shows follicular proliferative lesion without a distinct tumor capsule. (B) The high-power view of Fig. 3A shows benign-appearing follicular cells. This lesion can be interpreted as a benign follicular nodule. (C) The specimen is densely hyalinized and paucicellular. (D) The high-power view of Fig. 3C reveals benign-appearing follicular cells in the hyalinized stroma, suggesting a benign follicular nodule. (E) The specimen shows a Hürthle cell proliferative lesion. (F) The high-power view of Fig. 3E reveals Hürthle cell proliferation and lymphoid aggregates. This lesion should be interpreted as a benign Hürthle cell proliferative lesion rather than Hürthle cell neoplasm. 
minate lesion" for category III in the histopathological diagnosis of $\mathrm{CNB}$ specimens while some pathologists prefer the term "AUS" $[28,65]$. Regardless of the terminology used, it is important for the pathologists to use only a single term, either indeterminate lesion, AUS, or FLUS.

The diagnosis of category III is appropriate when a follicular proliferative lesion shows focal nuclear atypia such as nuclear enlargement with pale chromatin, irregular nuclear membrane, and nuclear grooves in a background of predominantly benignappearing follicles. A microfollicular proliferative lesion separated by a fibrous capsule from the surrounding normal parenchyma suggests a diagnosis of follicular neoplasm (see category IV). If a fibrous capsule or adjacent nonlesional tissue is not identified in a CNB specimen that shows a predominantly microfollicular or trabecular growth pattern, it is reasonable to classify the lesion under diagnostic category III because it is uncertain whether the nodule has a fibrous capsule. A multidisciplinary approach to a thyroid nodule can improve the preoperative diagnostic accuracy of FNA and CNB specimens [9]. Macrofollicular lesions are usually diagnosed as benign on FNA specimens. When US images show a dominant solitary nodule and the CNB specimen microscopically reveals a follicular proliferative lesion with a definite fibrous capsule, then the CNB specimen is diagnosed under category IV "follicular neoplasm," even in case of a macrofollicular lesion.

Category III should be subclassified according to nuclear atypia, histologic growth patterns, cell type, and other histological features because the subclassification suggests different histological features and a risk of malignancy in the thyroid nodules [65]. A subcategory of nuclear atypia indicates that papillary thyroid carcinoma must be ruled out whereas architectural atypia cannot exclude follicular neoplasm. The following common scenarios may be encountered in case of follicular proliferative lesions.

\section{IIla. Indeterminate follicular lesion with nuclear atypia}

Examples in this category include follicular proliferative lesions with focal nuclear atypia (Fig. 4A, B), follicular proliferative lesions with equivocal or questionable nuclear atypia, and atypical follicular cells embedded in a fibrotic or hyalinized stroma. This subcategory increases the risk of papillary carcinoma; however, the diagnosis does not reveal the characteristic histological features.

\section{IIIb. Indeterminate follicular lesion with architectural atypia}

Examples in this category include microfollicular proliferative lesions lacking a fibrous capsule or the adjacent nontumor tissue in the specimen; solid or trabecular follicular lesions lacking a fibrous capsule or adjacent nontumor tissue in the specimen (Fig. 4C, D). This subcategory exhibits no nuclear atypia. Some pathologists prefer category III "indeterminate follicular lesion" for a macrofollicular proliferative lesion with a definite fibrous capsule because a macrofollicular pattern is a characteristic of benign thyroid diseases.

\section{IIIc. Indeterminate follicular lesion with nuclear and architectural atypia}

In this category, follicular proliferative lesions show both nuclear and architectural atypia, but lack a fibrous capsule or the adjacent nontumor tissue in the specimen (Fig. 4E, F). Nuclear atypia is mild but lacking typical nuclear features of papillary carcinoma. Architectural atypia suggests microfollicular, solid, or trabecular proliferation. NIFTP is more frequently found in this subcategory [12].

\section{IIId. Indeterminate follicular lesion with Hürthle cell changes}

Follicular proliferative lesion is comprised exclusively of Hürthle cells, but the specimen lacks a fibrous capsule or the adjacent nontumor tissue (Fig. 5A, B). When Hürthle cell lesion is admixed with lymphoid aggregates, the $\mathrm{CNB}$ specimen should be diagnosed as benign Hürthle cell proliferative lesion (Fig. 3E, F).

\section{IIle. Indeterminate lesion, not otherwise specified}

This category includes follicular proliferative lesions with psammoma bodies but lacking nuclear features of papillary carcinoma; rare cases not explicitly described elsewhere in category III. Pseudo-psammomatous calcifications found in follicular lumens occur in Hürthle cell neoplasms and differ from true psammoma bodies found in papillary carcinoma (Fig. 5C, D).

\section{Follicular neoplasm}

In CNB and FNA, the term "follicular neoplasm" is used to encompass neoplastic lesions with a follicular proliferative pattern (e.g., cellular nodular hyperplasia, follicular adenoma, NIFTP, follicular carcinoma, follicular variant of papillary carcinoma, follicular variant of medullary carcinoma) $[26,86,87]$. In TBSRTC, the terms "follicular neoplasm" and "suspicious for a follicular neoplasm" were equally acceptable but were not intended to separately denote two different interpretations. Only a single terminology is recommended for use in this category. The histological diagnosis of "follicular neoplasm" in a CNB specimen is based on the presence of a fibrous capsule and microscopic fea- 

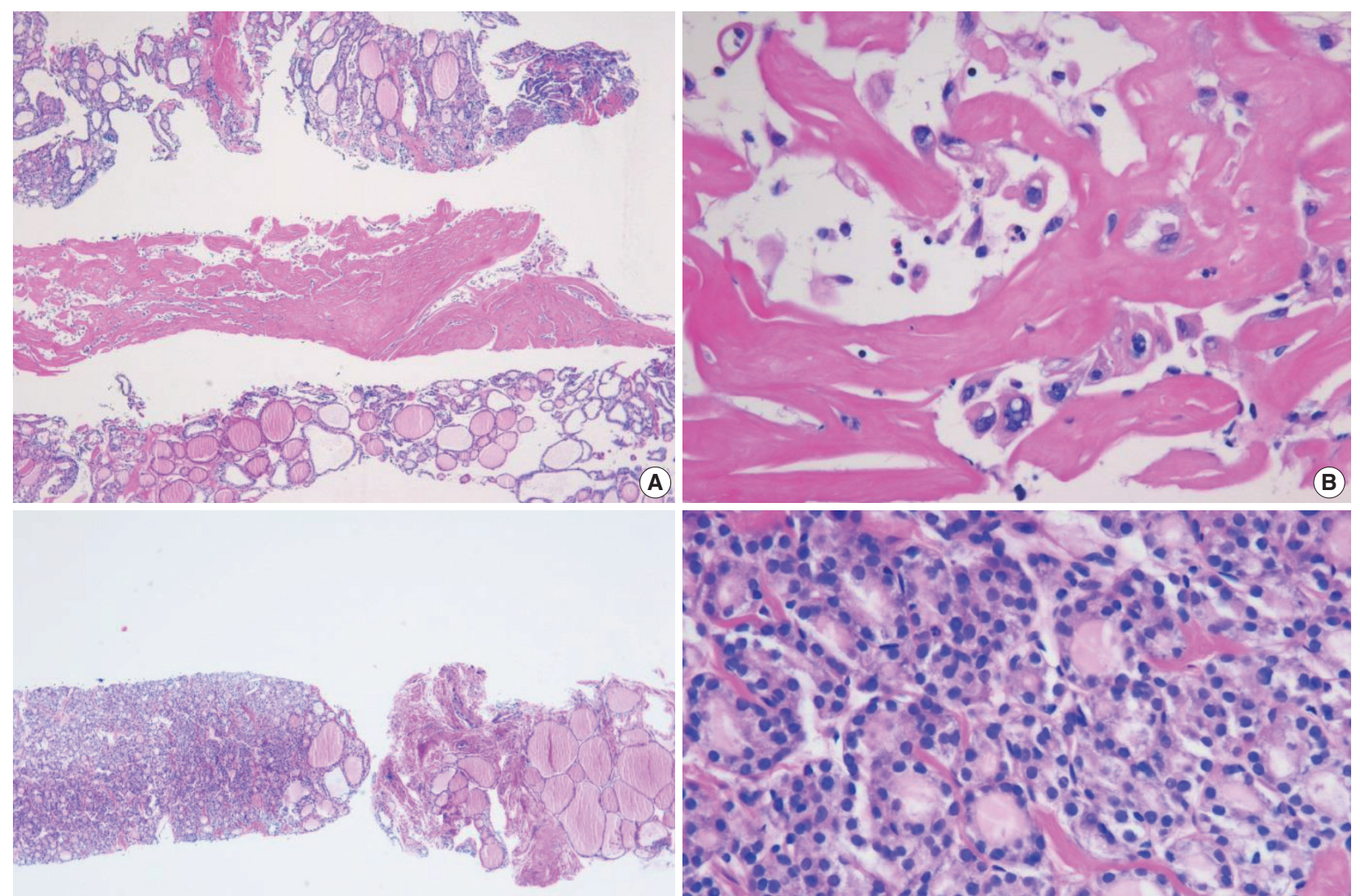

(c)
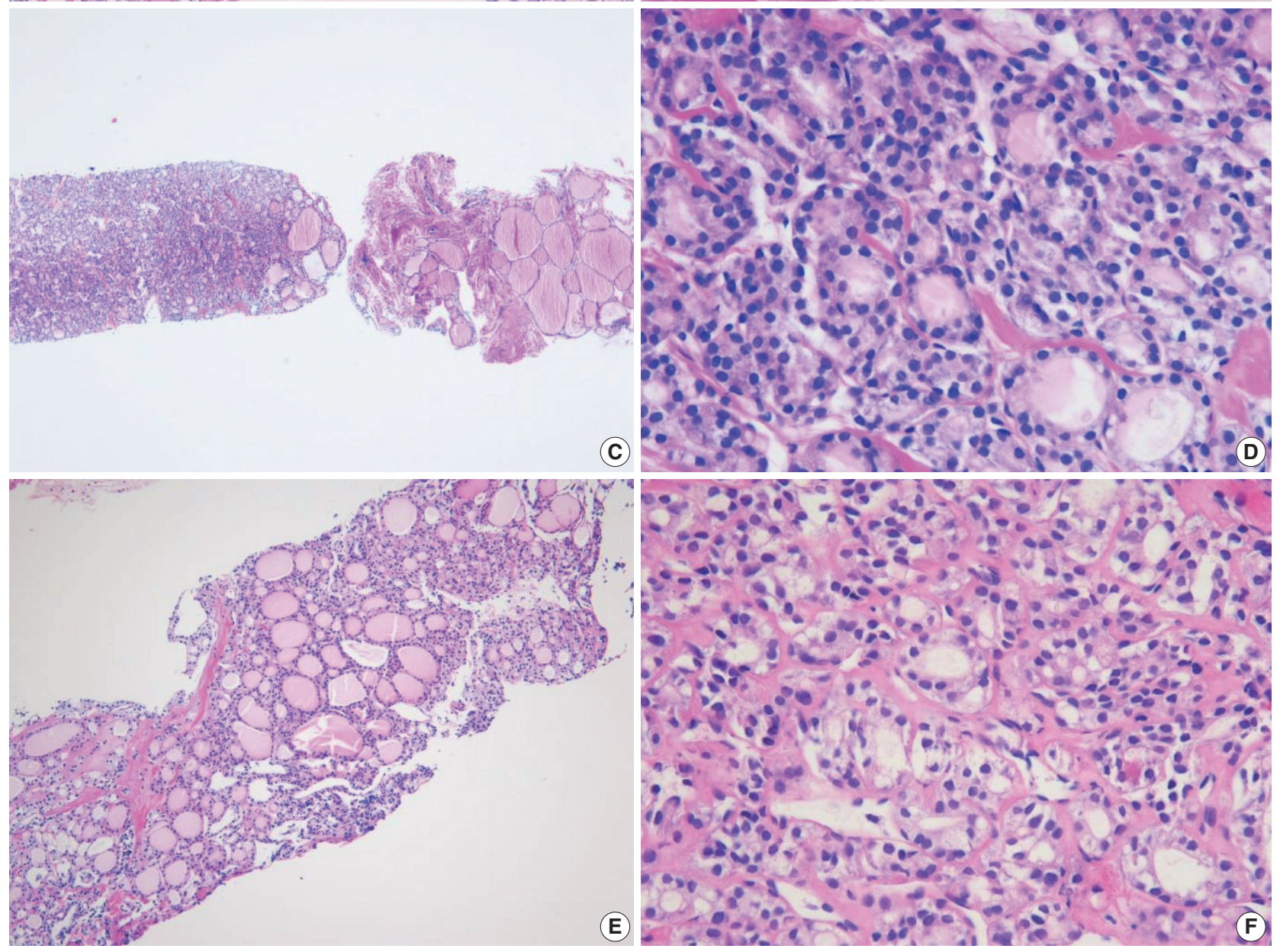

Fig. 4. Examples of indeterminate follicular lesion (category III) in thyroid core needle biopsy. (A) The middle one in the three biopsy cores shows densely hyalinized stroma. (B) The high-power view of Fig. 4A reveals atypical cells with nuclear atypia embedded in the hyalinized stroma. This lesion can be interpreted as indeterminate follicular lesion with nuclear atypia (category llla). (C) The specimen shows microfollicular proliferation and adjacent thyroid parenchyma. The lesion does not contain a fibrous capsule that is required to establish a diagnosis of follicular neoplasm. (D) The high-power view of Fig. 4C reveals microfollicular growth and absence of nuclear atypia. This lesion can be interpreted as indeterminate follicular lesion with architectural atypia (category IIIb). (E) The specimen shows microfollicular proliferation lacking a fibrous capsule and adjacent thyroid parenchyma in the specimen. (F) The high-power view of Fig. 4E reveals microfollicular growth, thin fibrous bands, and mild nuclear atypia, suggesting indeterminate follicular lesion with nuclear and architectural atypia (category IIIc). 

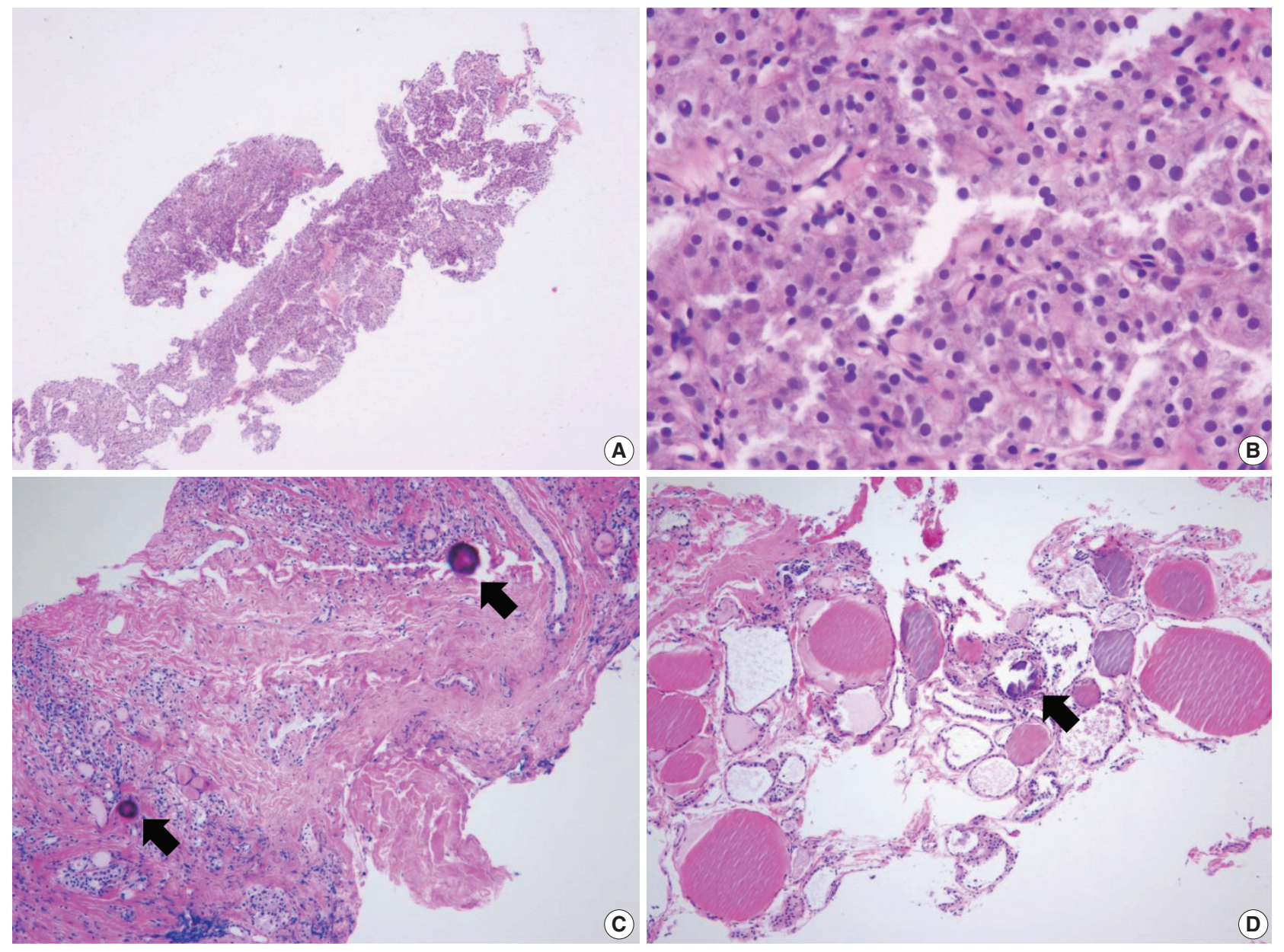

Fig. 5. (A) Specimen showing Hürthle cell proliferative lesion lacking a fibrous capsule or adjacent nonlesional thyroid tissue. (B) The highpower view of Fig. $5 \mathrm{~A}$ reveals trabecular growth of Hürthle cells without nuclear atypia, suggesting indeterminate follicular lesion with Hürthle cell changes (category IIId). Psammoma bodies (arrow) are found in a background of Hashimoto's thyroiditis (C) and normal thyroid tissue (D). These specimens lack nuclear features of papillary carcinoma and can be interpreted as indeterminate lesion, not otherwise specified (category llle).

tures that differ from the adjacent thyroid parenchyma (Fig. 6). In this category, follicular cells do not show typical nuclear features associated with papillary carcinoma. Papillary structure is often seen in hyperfunctioning follicular adenoma and follicular adenoma associated with papillary hyperplasia. The distinction is based on preserved cell polarity and lack of typical nuclear features of papillary carcinoma.

It is important to identify a well-formed fibrous capsule for the diagnosis of follicular neoplasm in the CNB specimen. Fibrous capsule is composed of fibrous connective tissue, which separates tumor cells from the adjacent thyroid tissue. However, it may be difficult to distinguish histologically between fibrous tumor capsule and intralesional fibrous band in small CNB samples (Fig. 7). Correlation between US and pathological findings can be used to differentiate fibrous tumor capsule from intralesional fibrosis. The location of the specimen notch in the US images represents the contents of tissue sample.

The FNA diagnosis for follicular neoplasm is primarily based on the microfollicular or trabecular architecture and the lack of colloid. In a CNB specimen, the growth patterns of a follicular neoplasm can be microfollicular, normofollicular, solid, or trabecular when the tumor fibrous capsule is identified in the sample. A CNB cannot discriminate between a follicular carcinoma and a follicular adenoma because the diagnosis of these neoplasms requires examination of the entire tumor capsule. Neoplastic follicular and Hürthle cells show architectural and cytologic features that differ from the adjacent nontumor thyroid tissue (Figs. 6-8). Hürthle cell neoplasm is classified under a clinically and genetically distinct tumor category according to the 2017 WHO Classification of Tumors of Endocrine Organs [29]. Thyroid CNB is used as a screening test similar to thyroid FNA for the detection of neoplastic nodule that requires lobectomy for a defini- 
tive histological diagnosis of surgical specimens. It is recommended that the category IV should be subclassified into four subgroups according to nuclear atypia, histologic growth patterns, and cell type. The subclassification reflects differences in histology and the risk of malignancy in the thyroid nodules [88].
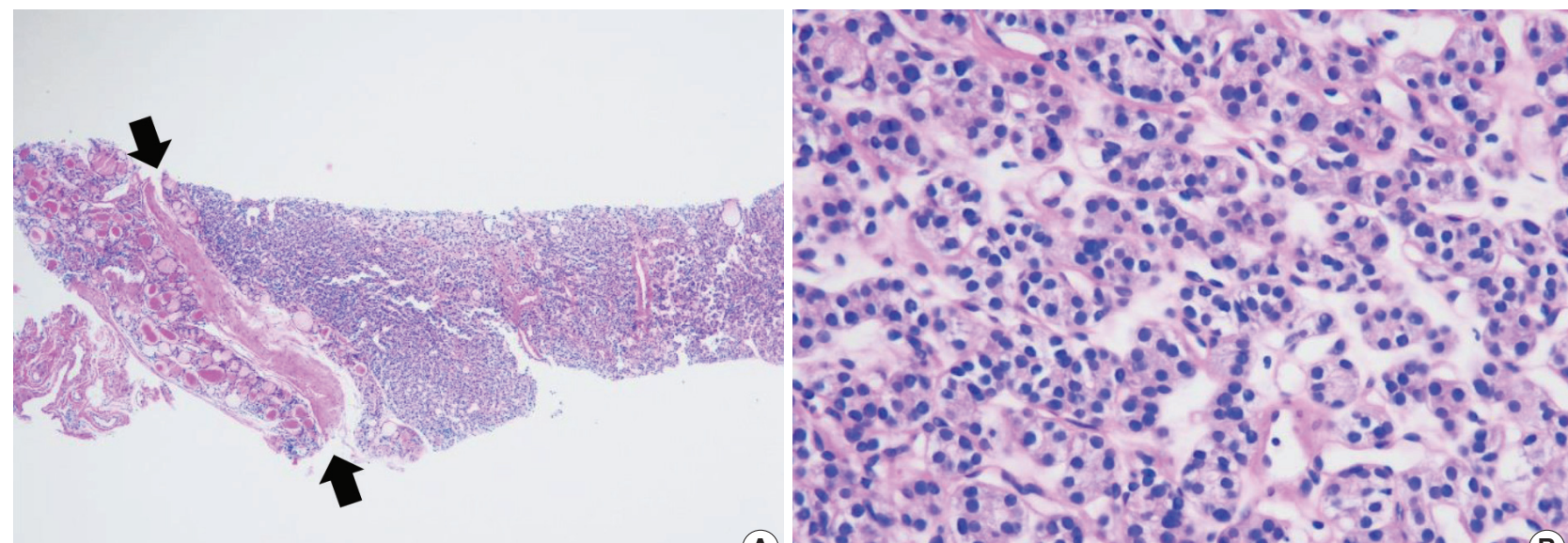

(A)
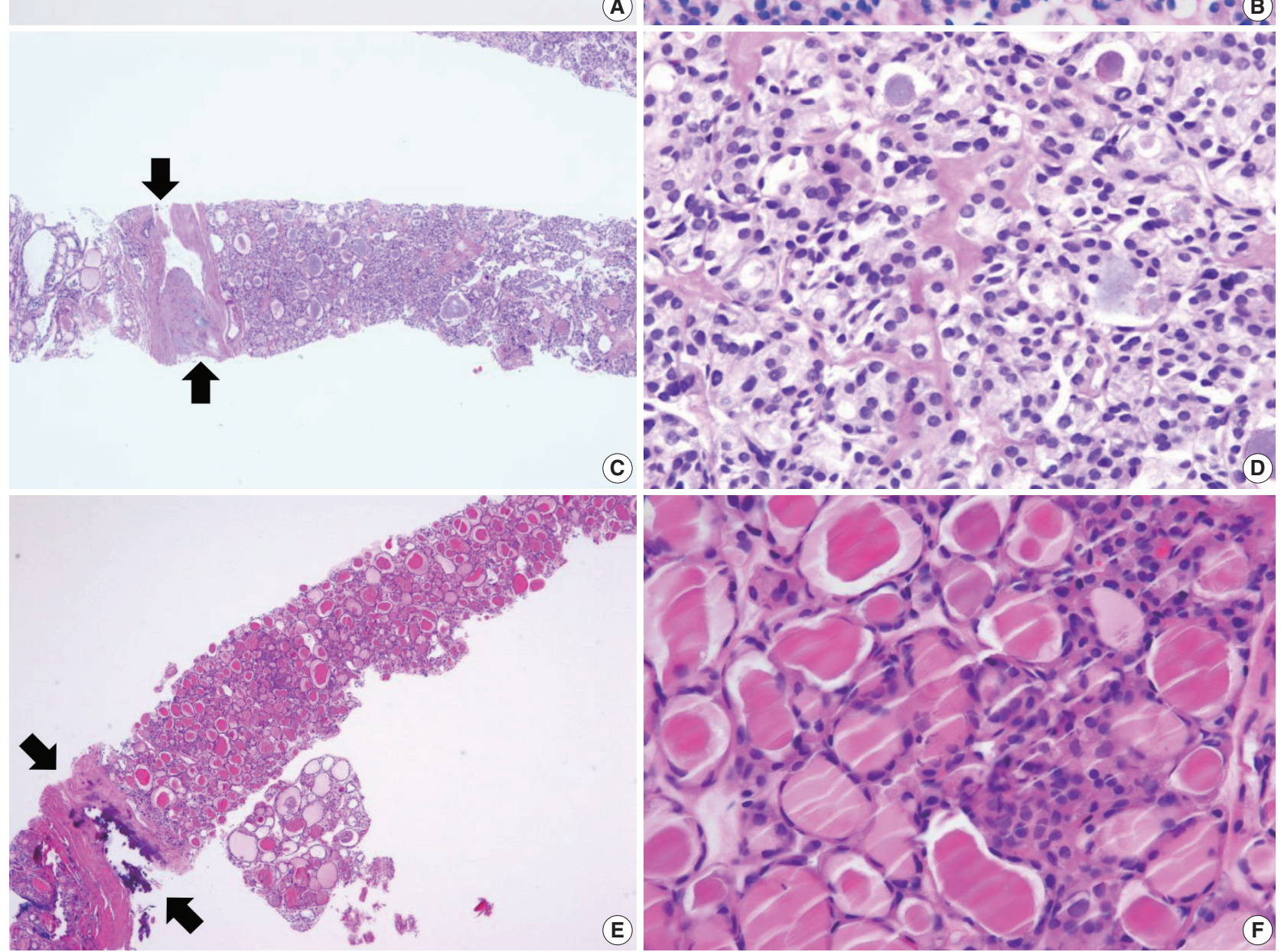

Fig. 6. Examples of follicular neoplasm (category IV) in thyroid core needle biopsy. (A) The low-power view shows a follicular proliferative lesion with a fibrous capsule (arrows). (B) The high-power view of Fig. 6A reveals microfollicular growth pattern and no nuclear atypia. This lesion can be interpreted as follicular neoplasm, conventional type (category IVa). (C) The specimen shows a follicular proliferative lesion with a thick fibrous capsule (arrows). (D) The high-power view of Fig. 6B reveals microfollicular growth pattern and follicular cells with nuclear atypia, suggesting follicular neoplasm with nuclear atypia (category IVb). (E, F) Another example of follicular neoplasm with nuclear atypia (category $\mathrm{IVb})$, in which, the lesion shows a fibrous capsule (arrows) nuclear atypia in focal areas (F). 


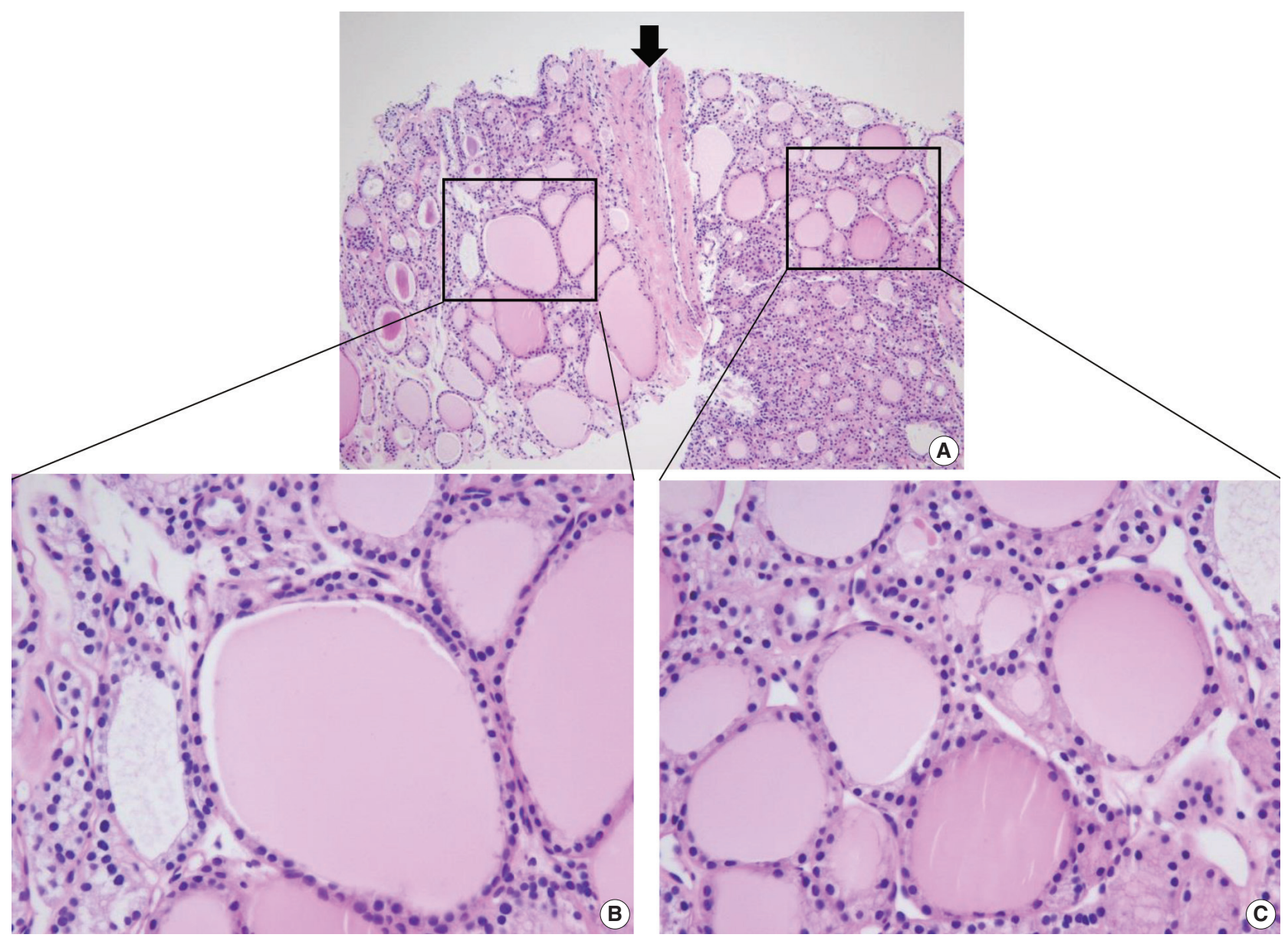

Fig. 7. Differential diagnosis of benign follicular nodule with a fibrous capsule (arrow) and follicular neoplasm (A). The specimen is composed of follicular proliferative lesion (right side), fibrous capsule (arrow), and adjacent normal thyroid parenchyma (left side). The morphology of follicular cell population within the nodule $(\mathrm{C})$ is identical to that of the adjacent thyroid parenchyma (B). The specimen should be interpreted as benign follicular nodule based on differences in growth pattern of the follicular neoplasm compared with the surrounding thyroid parenchyma.

\section{IVa. Follicular neoplasm, conventional type}

This category includes the following types of neoplasm: a microfollicular proliferative lesion with a fibrous capsule (Fig. 6A, B); a mixed microfollicular and normofollicular proliferative lesion with a fibrous capsule; a solid or trabecular follicular lesion with a fibrous capsule; a follicular proliferative lesion showing papillary structure and fibrous capsule but lacking nuclear features of papillary carcinoma.

\section{IVb. Follicular neoplasm with nuclear atypia}

Focal nuclear atypia in follicular neoplasm raises the possibility of NIFTP and follicular variants of papillary carcinoma (Fig. 6C, D) $[57,88-90]$. Before the NIFPT era, this subcategory frequently turned out to be a follicular variant of papillary carcinoma after surgery $[89,90]$.

\section{IVc. Hürthle cell neoplasm}

A Hürthle cell proliferative lesion with a fibrous capsule should be diagnosed in this category (Fig. 8). Hürthle cells exhibiting characteristic nuclear features of papillary carcinoma are papillary carcinoma cells, and therefore should not be diagnosed as Hürthle cell neoplasms. Hashimoto's thyroiditis often presents as a solitary nodule or as a dominant thyroid nodule. CNB sampling from a nodule of Hashimoto thyroiditis shows Hürthle cell proliferation in microfollicles, macrofollicles, or trabecula, which may contain a fibrous capsule surrounding the lesion that could be misinterpreted as Hürthle cell neoplasms (Fig. 3E, F). Careful search for lymphocyte and plasma cell infiltration is essential to distinguish such cases from Hürthle cell neoplasm. The Hürthle cell proliferative lesion admixed with lymphocytes and plasma cells should be diagnosed as benign Hürthle cell proliferative lesion rather than Hürthle cell neoplasm or indeterminate follicular 

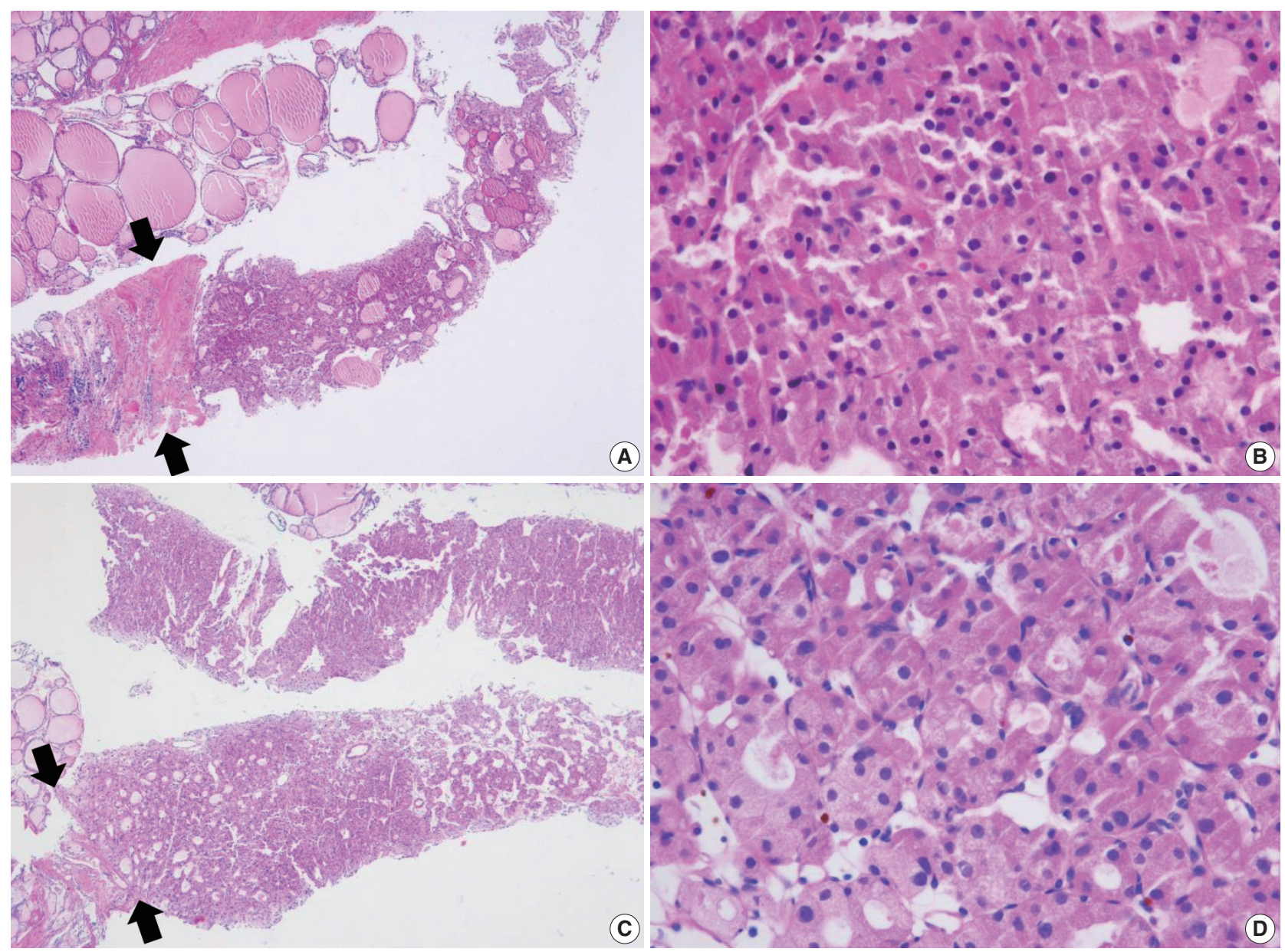

Fig. 8. Thyroid core needle biopsy showing Hürthle cell neoplasm (category IVC). The images in the left (A, C) and right (B, D) columns show low-power findings and corresponding high-power views, respectively. The tumor capsule (arrows) can be thick (A) or thin (C).

lesion with Hürthle cell changes.

\section{IVd. Follicular neoplasm, not otherwise specified}

This category includes rare cases not explicitly described elsewhere in category IV.

\section{Suspicious for malignancy}

The diagnosis of "suspicious for malignancy" is established when histological features are strongly suspicious for malignancy but are insufficient or equivocal for a definitive diagnosis of malignancy. In this category, a lesion may be suspicious for papillary thyroid carcinoma (Fig. 9), medullary thyroid carcinoma, poorly differentiated thyroid carcinoma, metastatic carcinoma, lymphoma, or show other suspicious findings. The diagnostic uncertainty in this category is generally caused by suboptimal sampling or low cellularity.

Follicular variants of papillary carcinoma and NIFTP share histologic features of follicular growth and nuclear features of papillary carcinoma, and cannot be discriminated by FNA alone. The diagnosis of papillary carcinoma by FNA requires either intranuclear pseudoinclusions, papillae, or psammoma bodies. In a CNB specimen, both areas of tumor and nontumor can be histologically evaluated. When a follicular proliferative lesion with nuclear features of papillary carcinoma shows capsular invasion in $\mathrm{CNB}$ specimens, the findings should be interpreted as papillary carcinoma. In the absence of capsular invasion, it should be interpreted as follicular neoplasm with nuclear atypia. However, when a fibrous capsule or adjacent nonlesional tissue is not identified in the CNB specimen that shows a predominantly follicular growth pattern and nuclear features of papillary carcinoma, the findings are best interpreted as suspicious for papillary carcinoma.

Ancillary immunohistochemical or molecular studies facilitate the diagnosis of $\mathrm{CNB}$ specimens with suspected malignancy. An immunostaining panel consisting of galectin-3, HBME1, cytokeratin 19, or CD56 facilitates the diagnosis of lesions suspi- 
cious for papillary thyroid carcinoma (Fig. 9) [91-93]. A combination of at least two immunostaining markers is recommended to improve the diagnostic accuracy [92]. The BRAF V600E mutations detected via molecular test or immunohistochemistry for BRAF VE1 antibody strongly suggest a diagnosis of papillary carcinoma (Fig. 9) [91]. A diagnosis of medullary thyroid carci-

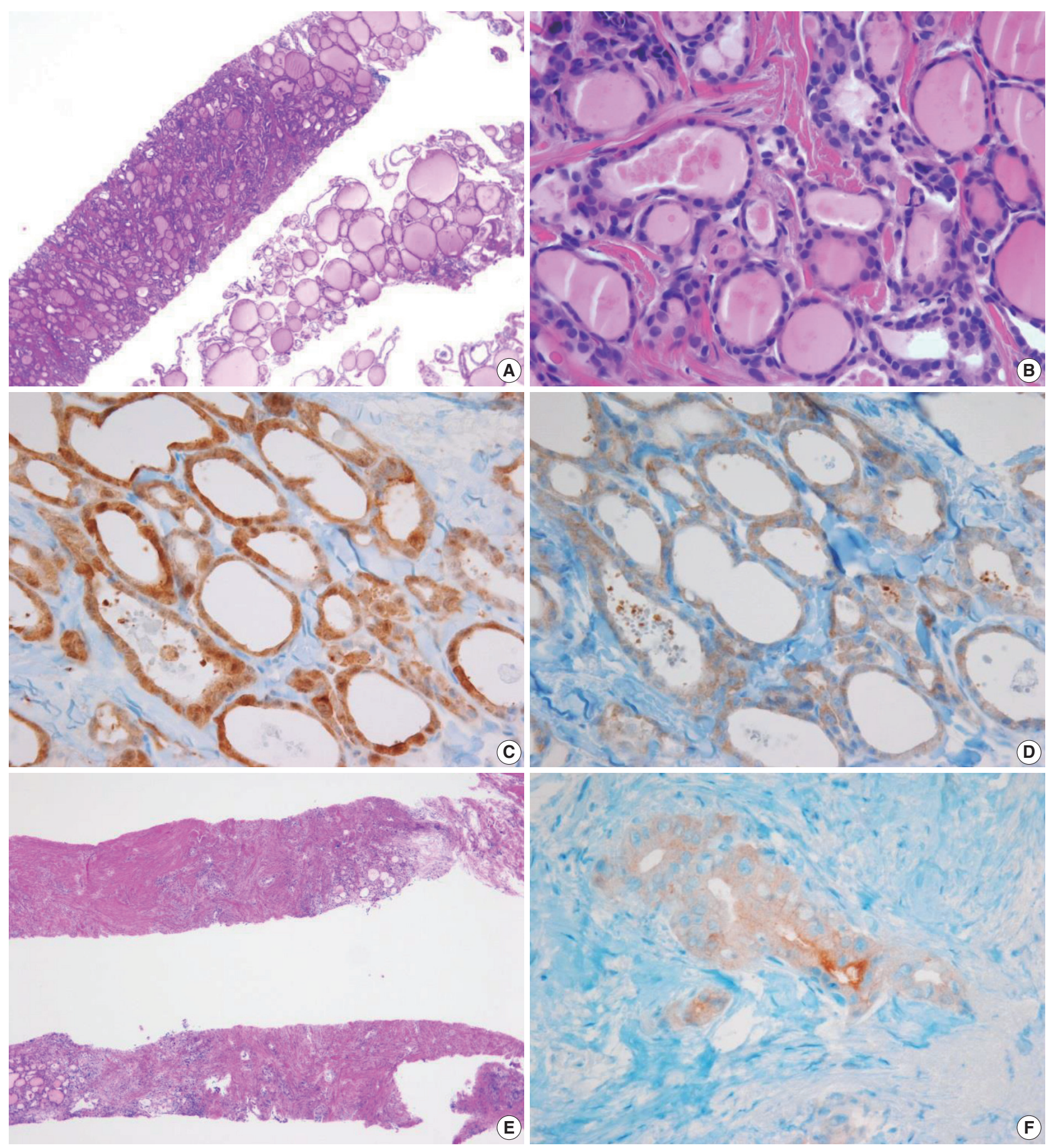

Fig. 9. (A) The specimen shows a follicular proliferative lesion with an ill-defined border showing a different morphology compared with adjacent normal thyroid tissue. (B) The high-power view in Fig. 9A reveals atypical follicular cells with nuclear atypia and fibrous bands. These morphological features can be interpreted as suspicious for papillary carcinoma (category V). In this case, immunohistochemical stains for galectin-3 (C) and BRAF VE1 (D, F) facilitate the diagnosis of papillary carcinoma. (E) A paucicellular, hyalinized follicular lesion exhibits morphological features pathognomonic for papillary carcinoma. The diagnosis of the lesion can be established as papillary carcinoma when atypical follicular cells in the specimen are positive for BRAF VE1 immunostaining (F). 
noma can be confirmed with positive immunostaining for calcitonin on the CNB specimen. A diagnosis of lymphoma is established using immunophenotyping studies on a CNB specimen that is suspicious for lymphoma [56].

\section{Malignant}

Most thyroid malignancies, except for follicular carcinoma/ Hürthle cell carcinoma, exhibit typical histological features and are easily diagnosed as a malignancy on a $\mathrm{CNB}$ specimen. The
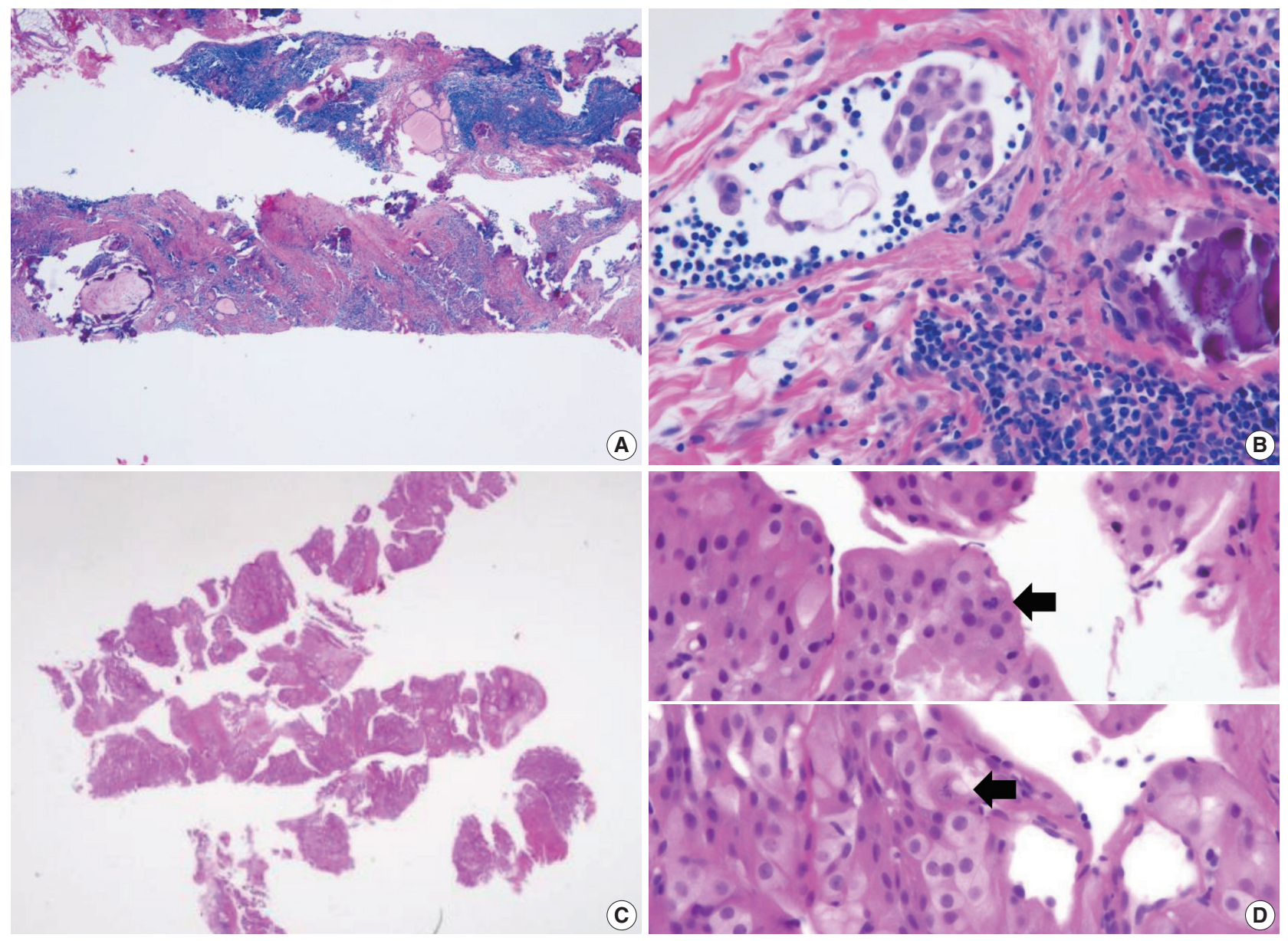

(C)
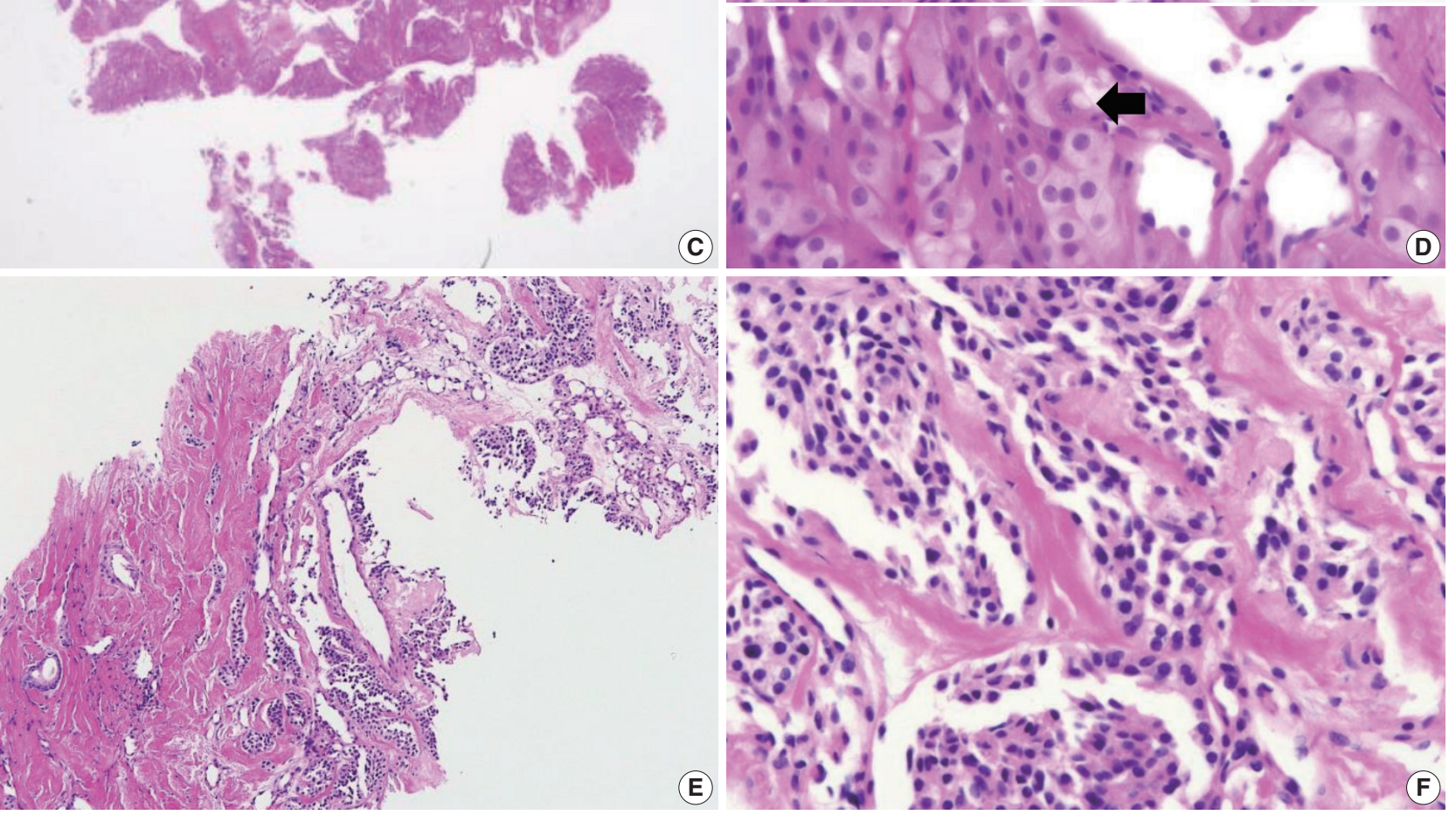

Fig. 10. Core needle biopsies of malignant thyroid tumors (category VI). (A, B) Diffuse sclerosing variant of papillary carcinoma. (C, D) Poorly differentiated carcinoma shows solid, trabecular, and insular growth patterns and mitosis (arrows) under high-power field. Medullary carcinoma shows typical histologic features under low-power field $(E)$ and high-power field (F). Nuclei of tumor cells are round to oval and carry coarsely granular chromatin. The cytoplasm is finely granular eosinophilic to amphophilic. 
category of thyroid malignancies includes the following diagnoses: papillary thyroid carcinoma (Fig. 10A, B), poorly differentiated carcinoma (Fig. 10C, D), medullary thyroid carcinoma (Fig. 10E, F), anaplastic thyroid carcinoma (Fig. 11A-C), lymphoma (Fig. 11D-F), and metastatic carcinoma.

\section{COMMON PITFALLS IN THE INTERPRETATION OF CORE NEEDLE BIOPSY}

The follicular cells in a CNB specimen appear smaller and show darker chromatin than is typical in a surgical specimen (Fig.
12A, B). Therefore, the nuclear features of papillary carcinoma are less prominent in a CNB specimen (Fig. 12C, D).

Nuclear artifacts that mimic intranuclear cytoplasmic pseudoinclusions in papillary carcinoma may also be present in benign follicular cells (Fig. 12E). The artifactual vacuoles or bubbles are irregular in shape and appear pale on staining, whereas intranuclear pseudoinclusions in papillary carcinoma are round and sharply delineated by the rim of the nuclear membrane, and exhibit cytoplasmic staining quality (Fig. 12F).

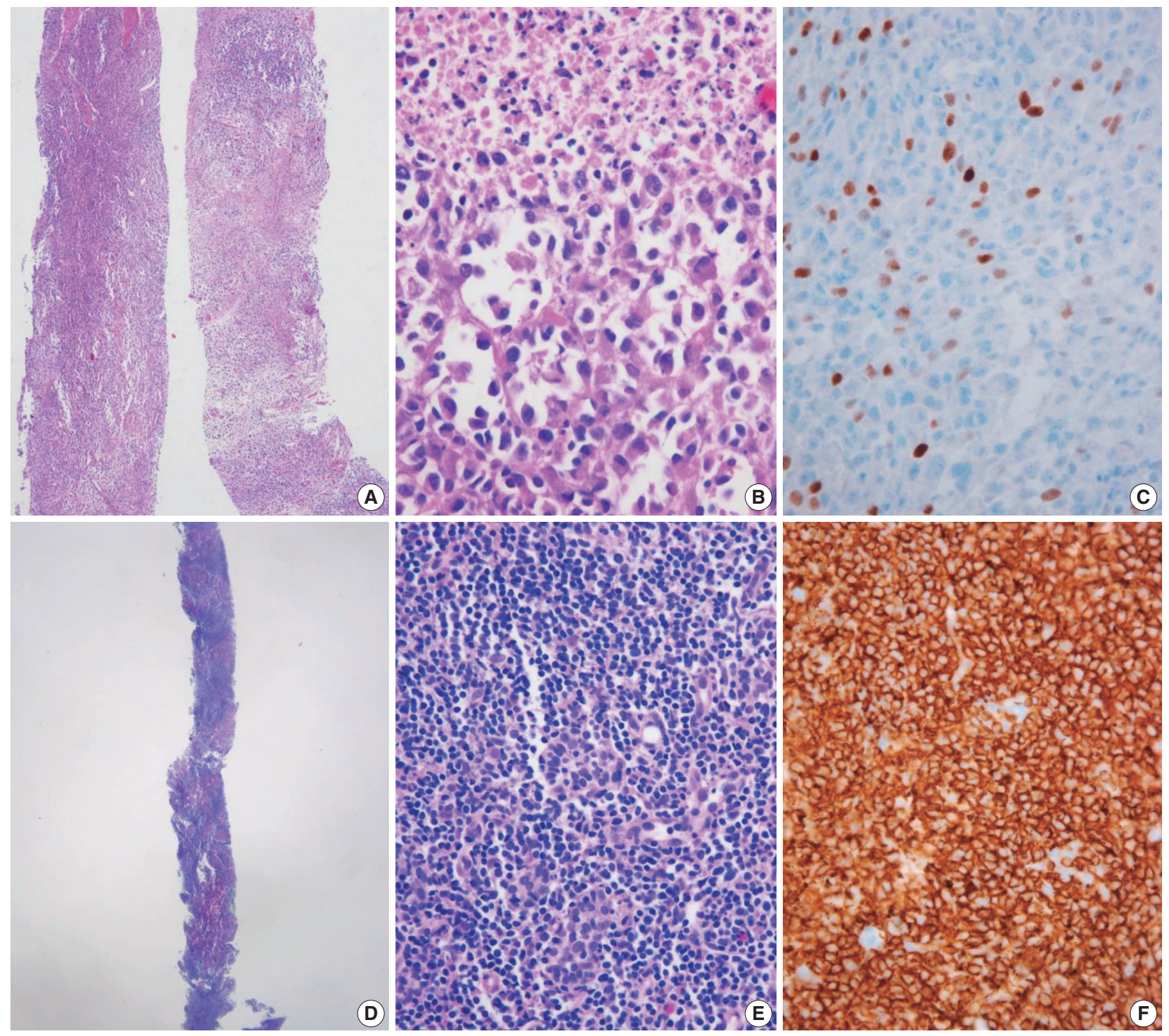

Fig. 11. Core needle biopsies of malignant thyroid tumors (category VI). (A) Anaplastic thyroid carcinoma shows diffuse growth infiltration, with no papillary or follicular structure. (B) The tumor cells show marked nuclear pleomorphism and necrosis. (C) PAX8 immunostaining is focally positive in this anaplastic thyroid carcinoma. (D) In extranodal marginal zone lymphoma of mucosa-associated tissue, the lymphoma cells infiltrate follicles and destroy normal parenchyma. (E) Lymphoepithelial lesions are shown. (F) Tumor cells are diffusely positive for CD20. 

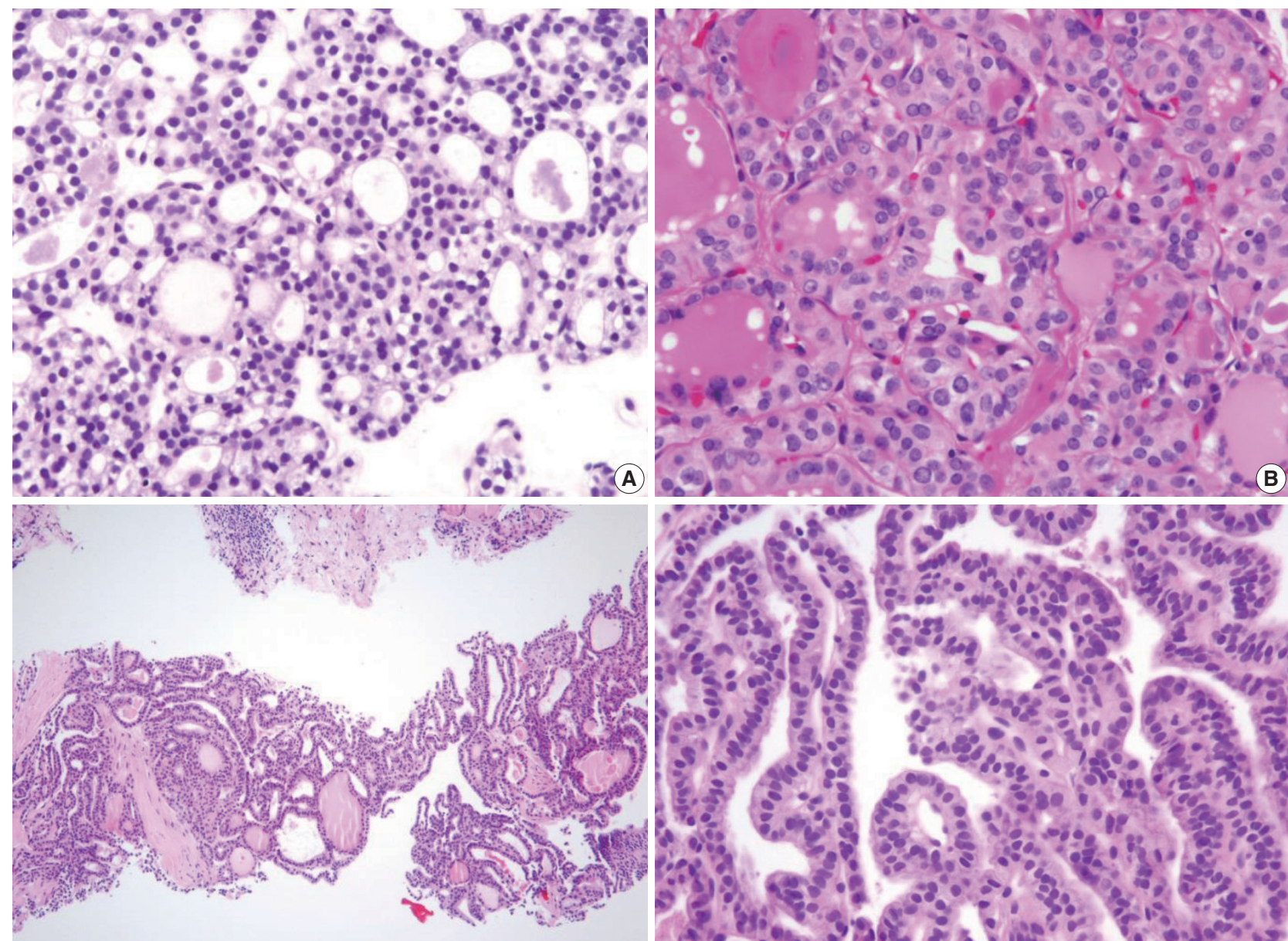

(c)
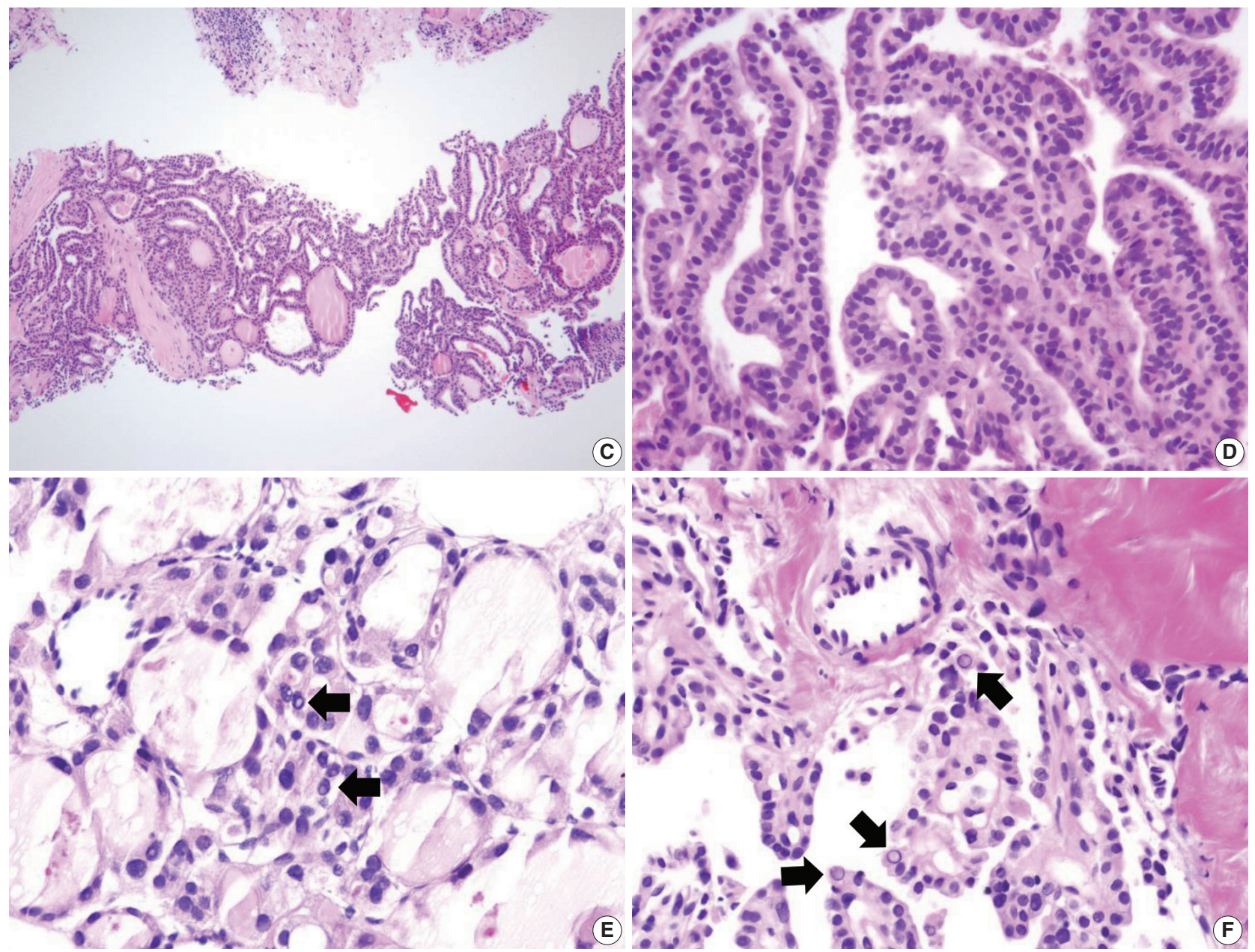

Fig. 12. Diagnostic pitfalls in thyroid core needle biopsy. Follicular cells are smaller and darker in core needle biopsy (A) compared with the resected specimen (B) in the same thyroid nodule. (C) The core needle biopsy shows histologic features of papillary carcinoma. (D) The highpower view of Fig. 12C shows nuclear overlapping and crowding. Nuclear chromatin is finely dispersed but nuclear clearance is not as prominent as in papillary carcinoma derived from routine formalin-fixed sections of the resected specimen. (E) Nuclear pseudoinclusion-like nuclear bubbles or vacuoles (arrows) are often seen in the core needle biopsy specimen of benign follicular nodule. These structures show empty appearance and lack a thick nuclear membrane rim. (F) Core needle biopsy of papillary carcinoma shows intranuclear pseudoinclusions (arrows) exhibiting the characteristic cytoplasmic staining and are sharply demarcated by a nuclear membrane. 


\section{CONCLUSION}

US-guided CNB represents an alternative procedure to overcome the challenges associated with FNA for the diagnosis of thyroid nodules. The main goal of thyroid CNB is to obtain a large amount of thyroid lesion with minimal morbidity, and to triage patients with thyroid disease who need surgical management. These practical guidelines serve as a clinical guide for successful thyroid CNB and provide a standardized system for pathology reporting of $\mathrm{CNB}$ specimens.

\section{ORCID}

Chan Kwon Jung: https://orcid.org/0000-0001-6843-3708

Jung Hwan Baek: https://orcid.org/0000-0003-0480-4754

Dong Gyu Na: https://orcid.org/0000-0001-6422-1652

Young Lyun Oh: https://orcid.org/0000-0002-9127-4642

Ka Hee Yi: https://orcid.org/0000-0002-1999-9841

Ho-Cheol Kang: https://orcid.org/0000-0002-0448-1345

\section{Author Contributions}

Conceptualization: CKJ, JHB.

Data curation: CKJ, JHB, DGN.

Formal analysis: CKJ, JHB, DGN.

Funding acquisition: $\mathrm{CKJ}$.

Investigation: CKJ, JHB, DGN, YLO, HCK.

Methodology: CKJ, JHB, DGN, KHY, YLO, HCK.

Project administration: $\mathrm{CKJ}$.

Resources: CKJ, JHB, DGN, KHY, YLO, HCK.

Supervision: CKJ, JHB.

Validation: CKJ, JHB, DGN, KHY, YLO, HCK.

Visualization: CKJ, JHB, DGN, KHY, YLO, HCK.

Writing-original draft: CKJ, JHB, DGN.

Writing—review \& editing: CKJ, JHB, DGN, KHY, YLO, HCK.

\section{Conflicts of Interest}

C.K.J. is the editor-in-chief of Journal of Pathology and Translational Medicine. He serves on the Board of Directors of the KTA and the Korean Society of Pathologists. J.H.B. is the president of the KSThR. D.G.N. serves on the KTA and KSThR Board of Directors. K.H.Y. served as a Director General of the KTA Board of Directors during 2017-2019. H.C.K. serves as a Director of Clinical Practice Guidelines Development Committee of the Korean Thyroid Association.

\section{Funding}

These practical guidelines were supported by KTA without support from any commercial sources. This project was also partially supported by a grant (2017R1D1A1B03029597) from the Basic Science Research Program through the National Research Foundation of Korea.

\section{Acknowledgments}

The authors would like to thank the members of KTA, KSThR, and the Endocrine Pathology Study Group of the Korean Society of Pathologists for their valuable expertise and suggestions throughout this study. This document was approved by the Clinical Practice Guidelines Development Committee of the KTA in October 2019. The following professional organizations reviewed and endorsed the final document: KSThR, Korean Endocrine Pathology Study Group, and Korean Endocrine Society.

\section{REFERENCES}

1. Pitman MB, Abele J, Ali SZ, et al. Techniques for thyroid FNA: a synopsis of the National Cancer Institute Thyroid Fine-Needle Aspiration State of the Science Conference. Diagn Cytopathol 2008; 36: 407-24.

2. Ha EJ, Lim HK, Yoon JH, et al. Primary imaging test and appropriate biopsy methods for thyroid nodules: guidelines by Korean Society of Radiology and National Evidence-Based Healthcare Collaborating Agency. Korean J Radiol 2018; 19: 623-31.

3. Ashcraft MW, Van Herle AJ. Management of thyroid nodules. II: Scanning techniques, thyroid suppressive therapy, and fine needle aspiration. Head Neck Surg 1981; 3: 297-322.

4. Bongiovanni M, Spitale A, Faquin WC, Mazzucchelli L, Baloch ZW. The Bethesda System for Reporting Thyroid Cytopathology: a meta-analysis. Acta Cytol 2012; 56: 333-9.

5. Alexander EK, Heering JP, Benson CB, et al. Assessment of nondiagnostic ultrasound-guided fine needle aspirations of thyroid nodules. J Clin Endocrinol Metab 2002; 87: 4924-7.

6. Orija IB, Pineyro M, Biscotti C, Reddy SS, Hamrahian AH. Value of repeating a nondiagnostic thyroid fine-needle aspiration biopsy. Endocr Pract 2007; 13: 735-42.

7. Nayar R, Ivanovic M. The indeterminate thyroid fine-needle aspiration: experience from an academic center using terminology similar to that proposed in the 2007 National Cancer Institute Thyroid Fine Needle Aspiration State of the Science Conference. Cancer 2009; 117: 195-202.

8. Yang J, Schnadig V, Logrono R, Wasserman PG. Fine-needle aspiration of thyroid nodules: a study of 4703 patients with histologic 
and clinical correlations. Cancer 2007; 111: 306-15.

9. Yassa L, Cibas ES, Benson CB, et al. Long-term assessment of a multidisciplinary approach to thyroid nodule diagnostic evaluation. Cancer 2007; 111: 508-16.

10. Bongiovanni M, Krane JF, Cibas ES, Faquin WC. The atypical thyroid fine-needle aspiration: past, present, and future. Cancer Cytopathol 2012; 120: 73-86.

11. Deveci MS, Deveci G, LiVolsi VA, Baloch ZW. Fine-needle aspiration of follicular lesions of the thyroid: diagnosis and follow-up. Cytojournal 2006; 3: 9.

12. Yoo C, Choi HJ, Im S, et al. Fine needle aspiration cytology of thyroid follicular neoplasm: cytohistologic correlation and accuracy. Korean J Pathol 2013; 47: 61-6.

13. Novoa E, Gurtler N, Arnoux A, Kraft M. Role of ultrasound-guided core-needle biopsy in the assessment of head and neck lesions: a meta-analysis and systematic review of the literature. Head Neck 2012; 34: 1497-503.

14. Na DG, Baek JH, Jung SL, et al. Core needle biopsy of the thyroid: 2016 consensus statement and recommendations from Korean Society of Thyroid Radiology. Korean J Radiol 2017; 18: 217-37.

15. Ha EJ, Baek JH, Lee JH, et al. Complications following US-guided core-needle biopsy for thyroid lesions: a retrospective study of 6,169 consecutive patients with 6,687 thyroid nodules. Eur Radiol 2017; 27: 1186-94.

16. Paja M, Del Cura JL, Zabala R, Korta I, Ugalde A, Lopez JI. Coreneedle biopsy in thyroid nodules: performance, accuracy, and complications. Eur Radiol 2019; 29: 4889-96.

17. Ha EJ, Suh CH, Baek JH. Complications following ultrasoundguided core needle biopsy of thyroid nodules: a systematic review and meta-analysis. Eur Radiol 2018; 28: 3848-60.

18. Na DG, Kim JH, Sung JY, et al. Core-needle biopsy is more useful than repeat fine-needle aspiration in thyroid nodules read as nondiagnostic or atypia of undetermined significance by the Bethesda system for reporting thyroid cytopathology. Thyroid 2012; 22: 468-75.

19. Samir AE, Vij A, Seale MK, et al. Ultrasound-guided percutaneous thyroid nodule core biopsy: clinical utility in patients with prior nondiagnostic fine-needle aspirate. Thyroid 2012; 22: 461-7.

20. Cao H, Kao RH, Hsieh MC. Comparison of core-needle biopsy and fine-needle aspiration in screening for thyroid malignancy: a systematic review and meta-analysis. Curr Med Res Opin 2016; 32: 1291-301.

21. Pyo JS, Sohn JH, Kang G. Core needle biopsy is a more conclusive follow-up method than repeat fine needle aspiration for thyroid nodules with initially inconclusive results: a systematic review and meta-analysis. J Pathol Transl Med 2016; 50: 217-24.

22. Trimboli P, Nasrollah N, Guidobaldi L, et al. The use of core needle biopsy as first-line in diagnosis of thyroid nodules reduces false negative and inconclusive data reported by fine-needle aspiration. World J Surg Oncol 2014; 12: 61.

23. Suh CH, Baek JH, Choi YJ, et al. Efficacy and safety of core-needle biopsy in initially detected thyroid nodules via propensity score analysis. Sci Rep 2017; 7: 8242.

24. Kim HC, Kim YJ, Han HY, et al. First-line use of core needle biopsy for high-yield preliminary diagnosis of thyroid nodules. AJNR Am J Neuroradiol 2017; 38: 357-63.

25. Hong MJ, Na DG, Kim SJ, Kim DS. Role of core needle biopsy as a first-line diagnostic tool for thyroid nodules: a retrospective cohort study. Ultrasonography 2018; 37: 244-53.

26. Cibas ES, Ali SZ. The 2017 Bethesda System for Reporting Thyroid Cytopathology. Thyroid 2017; 27: 1341-6.

27. Baek JH, Na DG, Lee JH, et al. Core needle biopsy of thyroid nodules: consensus statement and recommendations. J Korean Soc Ultrasound Med 2013; 32: 95-102.

28. Jung CK, Min HS, Park HJ, et al. Pathology reporting of thyroid core needle biopsy: a proposal of the Korean Endocrine Pathology Thyroid Core Needle Biopsy Study Group. J Pathol Transl Med 2015; 49: 288-99.

29. Lloyd RV, Osamura RY, Klöppel G, Rosai J. WHO classification of tumours of endocrine organs. 4th ed. Lyon: IARC Press, 2017; 66103

30. Gharib H, Papini E, Garber JR, et al. American Association of Clinical Endocrinologists, American College of Endocrinology, and Associazione Medici Endocrinologi medical guidelines for clinical practice for the diagnosis and management of thyroid nodules: 2016 update. Endocr Pract 2016; 22: 622-39.

31. Haugen BR, Alexander EK, Bible KC, et al. 2015 American Thyroid Association management guidelines for adult patients with thyroid nodules and differentiated thyroid cancer: The American Thyroid Association Guidelines Task Force on Thyroid Nodules and Differentiated Thyroid Cancer. Thyroid 2016; 26: 1-133.

32. Baloch ZW, Cibas ES, Clark DP, et al. The National Cancer Institute Thyroid fine needle aspiration state of the science conference: a summation. Cytojournal 2008; $5: 6$.

33. Perros P, Boelaert K, Colley S, et al. Guidelines for the management of thyroid cancer. Clin Endocrinol (Oxf) 2014; 81 Suppl 1: 1-122.

34. Yim Y, Baek JH. Core needle biopsy in the management of thyroid nodules with an indeterminate fine-needle aspiration report. Gland Surg 2019; 8(Suppl 2): S77-S85.

35. Jung CK, Baek JH. Recent advances in core needle biopsy for thyroid nodules. Endocrinol Metab (Seoul) 2017; 32: 407-12.

36. Suh CH, Baek JH, Kim KW, et al. The role of core-needle biopsy for thyroid nodules with initially nondiagnostic fine-needle aspiration 
results: a systematic review and meta-analysis. Endocr Pract 2016; 22: 679-88.

37. Paja M, del Cura JL, Zabala R, et al. Ultrasound-guided core-needle biopsy in thyroid nodules: a study of 676 consecutive cases with surgical correlation. Eur Radiol 2016; 26: 1-8.

38. Suh CH, Baek JH, Lee JH, et al. The role of core-needle biopsy as a first-line diagnostic tool for initially detected thyroid nodules. Thyroid 2016; 26: 395-403.

39. Sung JY, Na DG, Kim KS, et al. Diagnostic accuracy of fine-needle aspiration versus core-needle biopsy for the diagnosis of thyroid malignancy in a clinical cohort. Eur Radiol 2012; 22: 1564-72.

40. Chung SR, Suh CH, Baek JH, Choi YJ, Lee JH. The role of core needle biopsy in the diagnosis of initially detected thyroid nodules: a systematic review and meta-analysis. Eur Radiol 2018; 28: 4909-18.

41. Screaton NJ, Berman LH, Grant JW. US-guided core-needle biopsy of the thyroid gland. Radiology 2003; 226: 827-32.

42. Yeon JS, Baek JH, Lim HK, et al. Thyroid nodules with initially nondiagnostic cytologic results: the role of core-needle biopsy. Radiology 2013; 268: 274-80.

43. Park KT, Ahn SH, Mo JH, et al. Role of core needle biopsy and ultrasonographic finding in management of indeterminate thyroid nodules. Head Neck 2011; 33: 160-5.

44. Lee KH, Shin JH, Oh YL, Hahn SY. Atypia of undetermined significance in thyroid fine-needle aspiration cytology: prediction of malignancy by US and comparison of methods for further management. Ann Surg Oncol 2014; 21: 2326-31.

45. Na DG, Min HS, Lee H, Won JK, Seo HB, Kim JH. Role of core needle biopsy in the management of atypia/follicular lesion of undetermined significance thyroid nodules: comparison with repeat fine-needle aspiration in subcategory nodules. Eur Thyroid J 2015; 4: 189-96.

46. Buxey K, Serpell J. Importance of core biopsy in the diagnosis of thyroid lymphoma. ANZ J Surg 2012; 82: 90.

47. Kwak JY, Kim EK, Ko KH, et al. Primary thyroid lymphoma: role of ultrasound-guided needle biopsy. J Ultrasound Med 2007; 26: 1761-5.

48. Nam M, Shin JH, Han BK, et al. Thyroid lymphoma: correlation of radiologic and pathologic features. J Ultrasound Med 2012; 31: 589-94.

49. Ha EJ, Baek JH, Na DG, et al. The role of core needle biopsy and its impact on surgical management in patients with medullary thyroid cancer: clinical experience at 3 medical institutions. AJNR Am J Neuroradiol 2015; 36: 1512-7.

50. Kwok A, Faigel DO. Management of anticoagulation before and after gastrointestinal endoscopy. Am J Gastroenterol 2009; 104: 3085-97.

51. Baek JH. Current status of core needle biopsy of the thyroid. Ultra- sonography 2017; 36: 83-5.

52. Del Cura JL, Zabala R, Corta I. US-guided interventional procedures: what a radiologist needs to know. Radiologia 2010; 52: 198-207.

53. Harvey JN, Parker D, De P, Shrimali RK, Otter M. Sonographically guided core biopsy in the assessment of thyroid nodules. J Clin Ultrasound 2005; 33: 57-62.

54. Nasrollah N, Trimboli P, Guidobaldi L, et al. Thin core biopsy should help to discriminate thyroid nodules cytologically classified as indeterminate: a new sampling technique. Endocrine 2013; 43: 659-65.

55. Zhang M, Zhang Y, Fu S, Lv F, Tang J. Thyroid nodules with suspicious ultrasound findings: the role of ultrasound-guided core needle biopsy. Clin Imaging 2014; 38: 434-8.

56. Hahn SY, Shin JH, Han BK, Ko EY, Ko ES. Ultrasonography-guided core needle biopsy for the thyroid nodule: does the procedure hold any benefit for the diagnosis when fine-needle aspiration cytology analysis shows inconclusive results? Br J Radiol 2013; 86: 20130007.

57. Min HS, Kim JH, Ryoo I, Jung SL, Jung CK. The role of core needle biopsy in the preoperative diagnosis of follicular neoplasm of the thyroid. APMIS 2014; 122: 993-1000.

58. Yoon RG, Baek JH, Lee JH, et al. Diagnosis of thyroid follicular neoplasm: fine-needle aspiration versus core-needle biopsy. Thyroid 2014; 24: 1612-7.

59. Ahn HS, Seo M, Ha SM, Kim HS. Comparison of the diagnostic efficacy of ultrasound-guided core needle biopsy with 18- versus 20gauge needles for thyroid nodules. J Ultrasound Med 2018; 37: 2565-74.

60. Lopez JI, Zabala R, Del Cura JL. Histological diagnosis of thyroid disease using ultrasound-guided core biopsies. Eur Thyroid J 2013; 2: 29-36.

61. Hahn SY, Shin JH, Oh YL. What is the ideal core number for ultrasonography-guided thyroid biopsy of cytologically inconclusive nodules? AJNR Am J Neuroradiol 2017; 38: 777-81.

62. Park HS, Baek JH, Gyu ND. Regarding "what is the ideal core number for ultrasonography-guided thyroid biopsy of cytologically inconclusive nodules?". AJNR Am J Neuroradiol 2017; 38: E53-4.

63. Chung SR, Baek JH, Choi YJ, et al. The role of core needle biopsy for the evaluation of thyroid nodules with suspicious ultrasound features. Korean J Radiol 2019; 20: 158-65.

64. Hong MJ, Sung JY, Baek JH, et al. Safety and efficacy of radiofrequency ablation for nonfunctioning benign thyroid nodules in children and adolescents in 14 patients over a 10-year period. J Vasc Interv Radiol 2019; 30: 900-6.

65. Chung SR, Baek JH, Lee JH, et al. Risk of malignancy according to the sub-classification of atypia of undetermined significance and suspicious follicular neoplasm categories in thyroid core needle 
biopsies. Endocr Pathol 2019; 30: 146-54

66. Ha EJ, Baek JH, Lee JH, et al. Core needle biopsy can minimise the non-diagnostic results and need for diagnostic surgery in patients with calcified thyroid nodules. Eur Radiol 2014; 24: 1403-9.

67. Yi KS, Kim JH, Na DG, et al. Usefulness of core needle biopsy for thyroid nodules with macrocalcifications: comparison with fineneedle aspiration. Thyroid 2015; 25: 657-64.

68. Na DG, Kim DS, Kim SJ, Ryoo JW, Jung SL. Thyroid nodules with isolated macrocalcification: malignancy risk and diagnostic efficacy of fine-needle aspiration and core needle biopsy. Ultrasonography 2016; 35: 212-9.

69. Ren J, Baek JH, Chung SR, Choi YJ, Jung CK, Lee JH. Degenerating thyroid nodules: ultrasound diagnosis, clinical significance, and management. Korean J Radiol 2019; 20: 947-55.

70. Khoo TK, Baker CH, Hallanger-Johnson J, et al. Comparison of ultrasound-guided fine-needle aspiration biopsy with core-needle biopsy in the evaluation of thyroid nodules. Endocr Pract 2008; 14 . 426-31.

71. Quinn SF, Nelson HA, Demlow TA. Thyroid biopsies: fine-needle aspiration biopsy versus spring-activated core biopsy needle in 102 patients. J Vasc Interv Radiol 1994; 5: 619-23.

72. Ha EJ, Baek JH, Lee JH. Ultrasonography-based thyroidal and perithyroidal anatomy and its clinical significance. Korean J Radiol 2015; 16: 749-66.

73. Nasrollah N, Trimboli P, Rossi F, et al. Patient's comfort with and tolerability of thyroid core needle biopsy. Endocrine 2014; 45: 79-83.

74. Jeong EJ, Chung SR, Baek JH, Choi YJ, Kim JK, Lee JH. A comparison of ultrasound-guided fine needle aspiration versus core needle biopsy for thyroid nodules: pain, tolerability, and complications. Endocrinol Metab (Seoul) 2018; 33: 114-20.

75. Kim HJ, Kim YK, Moon JH, Choi JY, Choi SI. Thyroid core needle biopsy: patients' pain and satisfaction compared to fine needle aspiration. Endocrine 2019; 65: 365-70.

76. Karstrup S, Balslev E, Juul N, Eskildsen PC, Baumbach L. US-guided fine needle aspiration versus coarse needle biopsy of thyroid nodules. Eur J Ultrasound 2001; 13: 1-5.

77. Polyzos SA, Anastasilakis AD. Clinical complications following thyroid fine-needle biopsy: a systematic review. Clin Endocrinol (Oxf) 2009; 71: 157-65.

78. Kakiuchi Y, Idota N, Nakamura M, Ikegaya H. A fatal case of cervical hemorrhage after fine needle aspiration and core needle biopsy of the thyroid gland. Am J Forensic Med Pathol 2015; 36: 207-9.

79. Tomoda C, Takamura Y, Ito Y, Miya A, Miyauchi A. Transient vocal cord paralysis after fine-needle aspiration biopsy of thyroid tumor
Thyroid 2006; 16: 697-9.

80. Choi SH, Kim EK, Kim SJ, Kwak JY. Thyroid ultrasonography: pitfalls and techniques. Korean J Radiol 2014; 15: 267-76.

81. Bergeron M, Beaudoin D. Simple core-needle biopsy for thyroid nodule, complicated tinnitus. Eur Thyroid J 2014; 3: 130-3.

82. Shah KS, Ethunandan M. Tumour seeding after fine-needle aspiration and core biopsy of the head and neck: a systematic review. Br J Oral Maxillofac Surg 2016; 54: 260-5.

83. Thavarajah R, Mudimbaimannar VK, Elizabeth J, Rao UK, Ranganathan $\mathrm{K}$. Chemical and physical basics of routine formaldehyde fixation. J Oral Maxillofac Pathol 2012; 16: 400-5.

84. Hewitt SM, Lewis FA, Cao Y, et al. Tissue handling and specimen preparation in surgical pathology: issues concerning the recovery of nucleic acids from formalin-fixed, paraffin-embedded tissue. Arch Pathol Lab Med 2008; 132: 1929-35.

85. Xiong Y, Yan L, Nong L, Zheng Y, Li T. Pathological diagnosis of thyroid nodules based on core needle biopsies: comparative study between core needle biopsies and resected specimens in 578 cases. Diagn Pathol 2019; 14: 10.

86. Cibas ES, Ali SZ; NCI Thyroid FNA State of the Science Conference. The Bethesda System For Reporting Thyroid Cytopathology. Am J Clin Pathol 2009; 132: 658-65.

87. Ali SZ. Thyroid cytopathology: Bethesda and beyond. Acta Cytol 2011; 55: 4-12.

88. Na HY, Woo JW, Moon JH, et al. Preoperative diagnostic categories of noninvasive follicular thyroid neoplasm with papillary-like nuclear features in thyroid core needle biopsy and its impact on risk of malignancy. Endocr Pathol 2019; 30: 329-39.

89. Bae JS, Choi SK, Jeon S, et al. Impact of NRAS mutations on the diagnosis of follicular neoplasm of the thyroid. Int J Endocrinol 2014; 2014: 289834.

90. Ustun B, Chhieng D, Van Dyke A, et al. Risk stratification in follicular neoplasm: a cytological assessment using the modified Bethesda classification. Cancer Cytopathol 2014; 122: 536-45.

91. Crescenzi A, Guidobaldi L, Nasrollah N, et al. Immunohistochemistry for BRAF(V600E) antibody VE1 performed in core needle biopsy samples identifies mutated papillary thyroid cancers. Horm Metab Res 2014; 46: 370-4.

92. Alshenawy HA. Utility of immunohistochemical markers in diagnosis of follicular cell derived thyroid lesions. Pathol Oncol Res 2014; 20: 819-28

93. El Demellawy D, Nasr AL, Babay S, Alowami S. Diagnostic utility of CD56 immunohistochemistry in papillary carcinoma of the thyroid. Pathol Res Pract 2009; 205: 303-9. 